\title{
Piecewise Frontogenesis from a Potential Vorticity Perspective: Methodology and a Case Study
}

\author{
Sebastien O. Korner and Jonathan E. Martin \\ Department of Atmospheric and Oceanic Sciences, University of Wisconsin-Madison, Madison, Wisconsin
}

(Manuscript received 4 November 1998, in final form 10 June 1999)

\begin{abstract}
Output from a numerical simulation by the University of Wisconsin Nonhydrostatic Modeling System is used to investigate the evolution of the surface frontal structure of an intense winter cyclone that occurred off the east coast of North America. Using the model data as input to the piecewise potential vorticity (PV) inversion method developed by Davis and Emanuel, the total surface frontogenesis is partitioned into contributions from discrete PV anomalies. These contributions are calculated using the nondivergent balanced winds associated with PV anomalies in the upper, interior, and surface layers as well as the balanced irrotational winds in what is termed piecewise frontogenesis.

The cyclone of interest developed into a nearly stationary, well-occluded storm characterized by a cutoff PV anomaly at the tropopause and near-surface frontogenesis concentrated in the warm frontal zone. During the open wave stage of the cyclone life cycle, this frontogenesis was produced largely by the balanced flow, particularly that portion of it associated with the upper-level PV anomaly. Throughout the remainder of the cyclone life cycle, the upper-level contribution to the frontogenesis retained a distribution similar to that of the total frontogenesis. After the cyclone occluded, however, the frontogenesis forced by the unbalanced portion of the flow became increasingly significant despite the persistent smallness of the unbalanced winds. In fact, a substantial portion of the lower-tropospheric frontogenesis observed in the occluded quadrant, including that along a developing bent-back front, was eventually associated with the unbalanced flow. These results suggest a potentially significant role is played by unbalanced motions in the development and maintenance of lowertropospheric frontal structure in midlatitude cyclones.
\end{abstract}

\section{Introduction}

Understanding the structure, evolution, and dynamics of the midlatitude cyclone has been a central goal of synoptic-dynamic meteorology for most of the twentieth century. A component of this sprawling research effort has been investigation of the dynamics of frontogenesis, and the resultant mesoscale precipitation distribution. The first comprehensive attempt to place the instantaneous structure and precipitation distribution of the midlatitude cyclone into the context of an identifiable life cycle was proposed by Bjerknes and Solberg (1922), in what became known as the Norwegian cyclone model. They proposed that cyclogenesis resulted from the growth of small perturbations on a deep, preexisting, globe-girdling polar front. The horizontal circulation associated with the growing perturbation, or wave, distorted the polar front into a cold front and a warm front. These fronts were identified as the seats of

Corresponding author address: Dr. Jonathan E. Martin, Department of Atmospheric and Oceanic Sciences, University of Wisconsin—Madison, 1225 W. Dayton Street, Madison, WI 53706.

E-mail: jon@meteor.wisc.edu precipitation production in cyclones as a result of the vertical motions associated with them, which were thought to result from the relative motion of air over the physical frontal surfaces.

A more satisfying physical link between frontal structure and precipitation production in cyclones was offered by frontogenesis theory (Petterssen 1936), especially in the pioneering work of Sawyer (1956) and Eliassen (1962). In this work, the frontal vertical motion was seen as a response to the thermal wind imbalance produced by differential horizontal advection by the primary (geostrophic) flow. Thus, the important mesoscale precipitation distribution in cyclones was seen as a dynamical consequence of the evolution of the cyclone's frontal structure.

Until recently, employment of what we term the "basic-state variables" approach has provided the predominant methodology for understanding and predicting the structure and evolution of midlatitude cyclones. This approach, in which temperature advection, divergence, vorticity, and omega are explicitly examined, offers a limited capacity to succinctly describe the various effects on the cyclone life cycle of the interactions that routinely occur among the different layers of the atmosphere. Relatively recently, midlatitude weather sys- 
tems, especially cyclones, have been investigated through the lens of potential vorticity (PV) analysis. This perspective, in which significant elements of the balanced dynamics of cyclones can be regarded in terms of the single scalar variable, PV, has afforded new perspectives on the $3 \mathrm{D}$ nature of cyclone processes. The "PV thinking" perspective requires consideration of the distribution of PV in the atmosphere, what that distribution implies about the wind field through PV inversion and whether or not (non-) conservation of PV is occurring. This perspective was pioneered by Kleinschmidt (1957) and revived by Hoskins et al. (1985, hereafter HMR). HMR described the concept of baroclinic instability from a PV perspective, which has led to a view of cyclogenesis in terms of PV that is both conceptual (e.g., Hoskins et al. 1985; Hoskins 1991; Raymond 1992) and analytical (in the form of case studies) (Hoskins and Berrisford 1988; Davis and Emanuel 1991; Davis 1992b; Davis et al. 1993; Whitaker and Davis 1994; Davis et al. 1996; Stoelinga 1996; Bresky and Colucci 1996; Ramos 1997; Morgan and NielsenGammon 1998). Most of these studies used a particular form of PV inversion known as piecewise potential vorticity inversion. This method, first envisioned by HMR and developed by Davis and Emanuel (1991), allows inversion of discrete pieces of the PV field to determine their respective influences on the circulation in the domain.

Thus far, studies employing piecewise PV inversion have focused primarily on the cyclogenesis problem, providing numerous insights into the nature of midlatitude cyclogenesis and the role of latent heating in cyclone evolution. However, with the exceptions of Ramos (1997) and Morgan (1999), this technique has not been employed in a study of frontogenesis despite the obvious importance of that process in the structural evolution of, and production and distribution of precipitation in, cyclones. Here we develop a companion PV view of the frontal evolution characteristic of midlatitude cyclones by partitioning a cyclone's circulation into contributions associated with discrete PV anomalies and calculating the near-surface frontogenesis associated with each circulation. Through this method, termed "piecewise frontogenesis," a significantly more detailed view of the processes, and features, governing frontal evolution during the cyclone life cycle emerges.

This paper will focus on explaining the concept of piecewise frontogenesis, outlining a methodology for its calculation, and diagnosing the influences of discrete portions of the PV field on the surface-based frontal structure of a robust midlatitude winter cyclone. To this end, the paper is organized as a case study of a recordbreaking winter storm that affected southern New England on 1 April 1997. We use output from a dynamically consistent numerical model, the University of Wisconsin Nonhydrostatic Modeling System (UW-NMS), as input to the Davis and Emanuel (1991) piecewise PV inversion method in this study. The numerical model is de- scribed in section 2. A description of the piecewise PV inversion method, along with the specific implementations used in this study, are given in section 3 . We also explain the technique used to partition the total frontogenesis and examine some schematic examples in that section. A synoptic description of the 1 April storm from a potential vorticity perspective is given in section 4 . Section 5 contains the results of the piecewise frontogenesis calculations for the 1 April case. Section 6 contains a discussion of these results emphasizing the role of the unbalanced flow in the structural evolution of the cyclone. Additionally, the important issue of defining an appropriate mean state for performing piecewise inversion is discussed. Section 7 will summarize the results and provide concluding remarks.

\section{Model description}

In order to perform the potential vorticity inversion and subsequent frontogenesis calculations for the 1 April storm, we use gridded output from a successful numerical simulation of the event performed using UWNMS. UW-NMS is described by Tripoli (1992a,b). The model employs a two-way interactive, moveable nesting scheme, which allows for simultaneous simulation of synoptic-scale forcing as well as frontal scale forcing. Prognostic variables carried by the model include $u, v$, $w$, and $\pi$ (Exner function); ice-liquid potential temperature $\theta_{i l}$; and total water mixing ratio, as well as the mixing ratios for a variety of precipitation particles.

Advection of the scalar variables is accomplished using a sixth-order Crowley scheme (Tremback et al. 1987), while the dynamic variables are advected using a second-order enstrophy-conserving leapfrog scheme (Sadourny 1975). Model physics include a radiation parameterization that predicts long- and shortwave radiative transfer in a cloudy atmosphere (Chen and Cotton 1983), and a predictive soil model with surface energy budget (Tremback and Kessler 1985). Liquid and ice processes are represented in the model by an explicit microphysics package that describes the evolution of cloud water, rainwater, pristine crystals, snow crystals, aggregate crystals, and graupel (Cotton et al. 1986; Flatau et al. 1989). A version of the Emanuel (1991) convective parameterization was employed, modified such that the convection equilibrates with the cyclone and frontal-scale vertical motion forcing.

For reasons discussed in section 3, the simulation contained two grids, an outer grid (grid 1) and an inner grid (grid 2) with horizontal resolutions of 160 and 80 $\mathrm{km}$, respectively. The data from grid 2 were predominantly used in this study. The geographic locations of these grids are shown in Fig. 1.

The model employed geometric height as the vertical coordinate with discretely blocked out topography similar to that used in the National Centers for Environmental Prediction's Eta Model. Forty vertical levels were used with the vertical grid spacing of $200 \mathrm{~m}$ in 


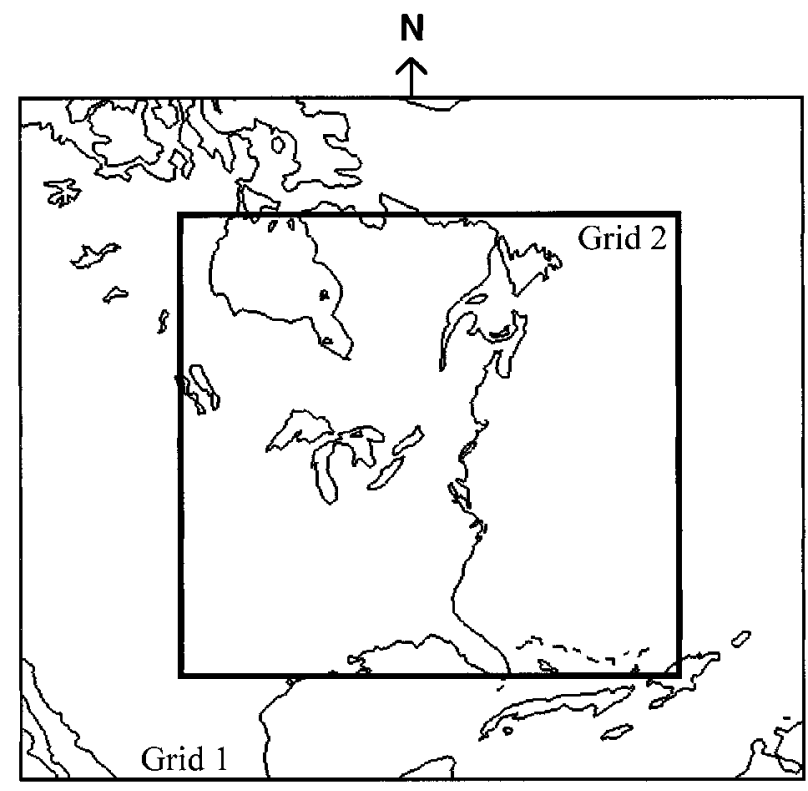

FIG. 1. Geographical locations of the two grids used in the numerical model simulation of this case. Results in this paper use grid 2 .

the lowest five grid levels with a gradual geometric stretching (by a factor of 1.07) above that such that the next 18 levels had an average spacing of $404 \mathrm{~m}$ and the top 17 levels had a spacing of $700 \mathrm{~m}$. The model top was located at $19.2 \mathrm{~km}$.

The model was initialized by interpolating directly from the 90-km NCEP nested grid model (NGM) initialization, which has $50-\mathrm{hPa}$ vertical resolution. Horizontal wind components, geopotential height, temperature, and mixing ratio were interpolated horizontally along constant pressure surfaces to the locations of the model grid points. Data were then vertically interpolated to the model grid levels. The lateral boundaries were updated at $6,12,18,24,36$, and $48 \mathrm{~h}$ from the NGM gridded forecasts using a Rayleigh-type absorbing layer. The simulation was initialized at 0000 UTC 31 March 1997 and was run for $48 \mathrm{~h}$.

A systematic verification of the model simulation will not be presented here. The simulation was checked against a series of subjective analyses (not shown) and found to be quite accurate. Given this accuracy, we confidently employ the gridded output from this simulation to perform piecewise potential vorticity inversion and subsequent piecewise frontogenesis calculations.

\section{Piecewise PV inversion}

\section{a. Technique and definitions}

The Ertel potential vorticity (EPV) was first defined by Rossby (1940) and Ertel (1942) as

$$
\mathrm{EPV}=\frac{1}{\rho} \boldsymbol{\eta} \cdot \nabla \theta
$$

where $\rho$ is the density, $\boldsymbol{\eta}$ the absolute vorticity vector, and $\theta$ the potential temperature. EPV is the potential vorticity for the complete atmospheric system; thus, it is conserved under the full primitive equations, given adiabatic, inviscid flow.

The goal of piecewise PV inversion is to recover the mass and momentum fields associated with discrete PV anomalies. The success of this endeavor, and therefore the usefulness of the resulting information, is limited by the approximations made to obtain a balanced system. The Davis and Emanuel (1991, hereafter DE) inversion method, which is employed in this study, assumes 1) hydrostatic balance and 2) that the magnitude of the irrotational component of the wind is much smaller than the magnitude of the nondivergent component (i.e., $\left.\left|\mathbf{v}_{\chi}\right| \ll\left|\mathbf{v}_{\psi}\right|\right)$. Applying these approximations to the divergence equation and (1) results in the invertibility statement for this system (DE):

$$
\begin{gathered}
\nabla^{2} \Phi=\nabla \cdot(f \nabla \psi)+\frac{2}{a^{4} \cos ^{2} \phi} \frac{\partial\left(\frac{\partial \psi}{\partial \lambda}, \frac{\partial \psi}{\partial \phi}\right)}{\partial(\lambda, \phi)} \\
\mathrm{EPV}=\frac{g \kappa \pi}{P}\left[\left(f+\nabla^{2} \psi\right) \frac{\partial^{2} \Phi}{\partial \pi^{2}}-\frac{1}{a^{2} \cos ^{2} \phi} \frac{\partial^{2} \psi}{\partial \lambda \partial \pi} \frac{\partial^{2} \Phi}{\partial \lambda \partial \pi}\right. \\
\left.-\frac{1}{a^{2}} \frac{\partial^{2} \psi}{\partial \phi \partial \pi} \frac{\partial^{2} \Phi}{\partial \phi \partial \pi}\right],
\end{gathered}
$$

where $\Phi$ is the geopotential, $\psi$ is the nondivergent streamfunction, $\lambda$ is the longitude, $\phi$ is the latitude, $a$ is the radius of the earth, $\kappa=R / c_{p}, P$ is pressure, and $\pi$ is the Exner function $\left[c_{p}\left(P / P_{o}\right)^{\kappa}\right]$, which serves as the vertical coordinate. Equation (2) is the Charney nonlinear balance equation (Charney 1955), which has been shown by prior studies to be an excellent approximation to observed flows (e.g., Davis et al. 1996), thus validating the application of PV diagnostics to the real atmosphere. Careful comparison of the model winds and the computed nondivergent balanced winds for the 1 April storm demonstrates that differences exist where expected (such as in trough and ridge axes), and that these differences became increasingly significant as the cyclone matured. Using PV computed from the model's wind and temperature fields, a total inversion is performed, solving this system of two equations simultaneously for $\psi$ and $\Phi$, with $\psi$ and $\Phi$ prescribed on the lateral boundaries and their vertical derivatives specified on the top and bottom boundaries. The potential temperature at 975 and $75 \mathrm{hPa}$ provides these Neumann boundary conditions on the horizontal boundaries. Also, negative values of $\mathrm{PV}$ are set to a small positive constant value $\left(0.01 \mathrm{PVU}\right.$, where $\left.1 \mathrm{PVU}=10^{-6} \mathrm{~m}^{2} \mathrm{~K} \mathrm{~kg}^{-1} \mathrm{~s}^{-1}\right)$. For a complete description of the boundary conditions, as well as the numerical methods used to solve the system of equations, the reader is referred to DE.

The model outputs its results at $50-\mathrm{hPa}$ resolution 


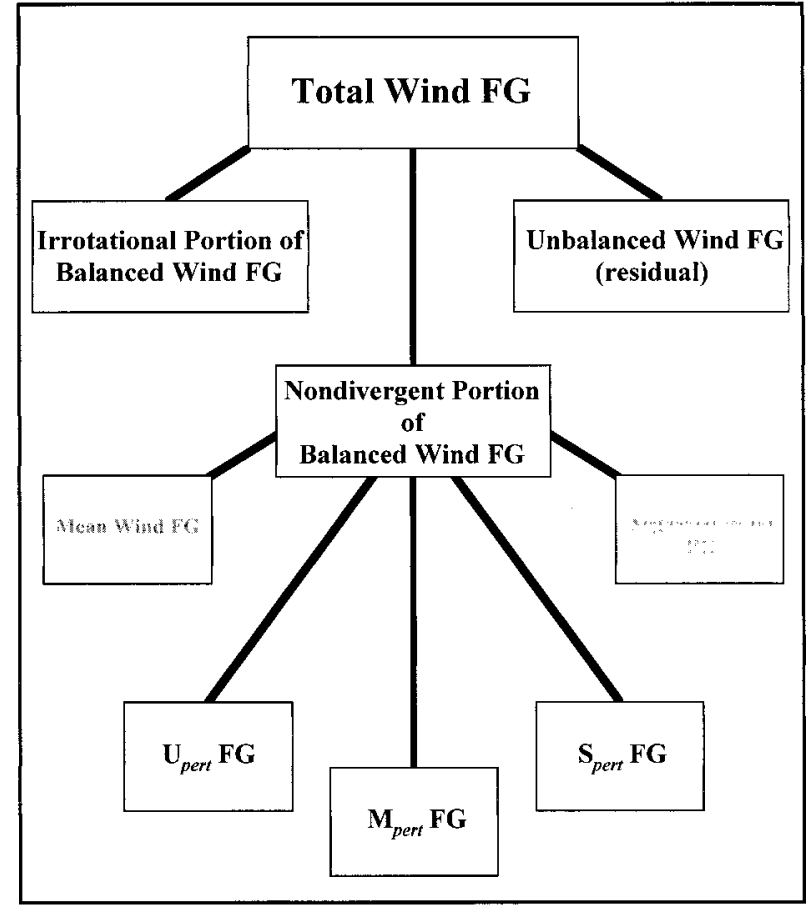

FIG. 2. Schematic representation of the partitioning of the total wind frontogenesis into components relevant to piecewise potentia vorticity inversion. The balanced wind refers to all that is recoverable from employing PV inversion, and the unbalanced wind refers to what is not recoverable (Davis et al. 1996) (see text). The irrotational balanced wind, nondivergent balanced wind, and unbalanced wind sum to the total wind. The mean nondivergent wind, $\mathbf{U}_{\text {pert }}$ wind, $\mathbf{M}_{\text {per }}$ wind, and $\mathbf{S}_{\text {pert }}$ wind sum to the total nondivergent, balanced wind.

(from 1000 to $50 \mathrm{hPa}$ ) onto a 90-km horizontal grid with properties equivalent to those of NMC grid 104. All of the vertical levels and a subset of the horizontal domain were used for the inversion. In the process of extracting the subset, the data is interpolated to a $1.0^{\circ}$ $\times 1.0^{\circ}$ grid, resulting in a $61 \times 33 \times 20$ domain. The coverage of the domain is roughly equivalent to that of the inner model grid (Fig. 1). After the final interpolation is complete, the PV is computed. The PV inversion performed for select times using the original, slightly higher resolution data provided results that did not differ from those presented in this paper. This is not unexpected, since the process of inversion naturally smoothes small-scale features (Davis et al. 1993). This smoothing of small-scale features, along with the accuracy of the two-grid run, is the primary reason a higher-resolution model run was not performed for this case.

In order to perform piecewise PV inversion, mean and perturbation fields must be defined. Since there exists no unique method for partitioning the PV, a choice must be made. Davis (1992a) performed a comprehensive evaluation of the benefits and drawbacks of different partitioning methods; however, for this study, only the method used by DE is employed. We considered a 96-h time window, which includes the $48 \mathrm{~h}$ from the model run discussed in section 2 and the $48 \mathrm{~h}$ previous to the start of that run. The latter is the result of two 24-h UW-NMS model runs, initialized at 0000 UTC 30 March 1997 and 0000 UTC 29 March 1997 (24 and $48 \mathrm{~h}$ before the primary simulation). The objective in computing a mean is to isolate the feature of interest in the PV field, thus placing it solely in the perturbation field. We subjectively define this mean to exclude time periods (within the 96-h window) during which the cyclone was nearly equivalent barotropic, which corresponded to times at which the low-level (below $3 \mathrm{~km}$ ) PV was greater than 1 PVU. By this method the $30 \mathrm{~h}$ from 1800 UTC 31 March through 0000 UTC 2 April were eliminated from the calculation of the mean. Thus, we used a 66-h time mean. Once the time mean is computed, it is subtracted from the instantaneous PV distribution at each discrete time. The difference between the time mean and the instantaneous PV is then referred to as the perturbation PV for that time. Further discussion on partitioning into mean and perturbation quantities will be undertaken in section 6 .

Effective use of piecewise potential vorticity inversion requires a meaningful partitioning of the atmosphere. The goals of partitioning are 1) to account for nearly all of the perturbation PV, while not inverting any of it more than once, and 2) to select the minimum number of partitions that adequately describe the features in question. One way to accomplish these goals is by grouping together potential vorticity anomalies with a common history (Davis 1992b). We therefore adopt a conventional three-way partitioning involving an upper layer, an interior layer, and a surface layer. The upper layer extends from 650 to $50 \mathrm{hPa}$ and is designed to isolate PV anomalies associated with undulations in the tropopause. In order to consider only upper-tropospheric/lower-stratospheric air in this category, we set the positive perturbation $\mathrm{PV}$ in this layer to $0.0 \mathrm{PVU}$ whenever the relative humidity is greater than or equal to $70 \%$. This method prevents the elimination of upperlevel downstream ridges, which often exist in moist air. The interior layer extends from 950 to $400 \mathrm{hPa}$ and is designed to isolate midtropospheric PV anomalies associated with latent heat release. Given that such latent heat release will occur in an environment at or near saturation, the PV in this layer is set to $0.0 \mathrm{PVU}$ whenever the relative humidity is less than $70 \%$. This guards against the scheme mistaking extruded stratospheric perturbation PV for perturbation PV "produced" by latent heat release. Finally, the surface layer extends from 950 to $850 \mathrm{hPa}$ and also includes the $975-\mathrm{hPa}$ potential temperature. This layer is designed to isolate the boundary potential temperature anomalies, which are equivalent to PV anomalies just above the surface (Bretherton 1966). The surface layer, however, also includes perturbation PV in the $950-850-\mathrm{hPa}$ layer. To ensure against redundancy with the interior layer, we set the perturbation $\mathrm{PV}$ in the $950-850-\mathrm{hPa}$ layer to $0.0 \mathrm{PVU}$ 


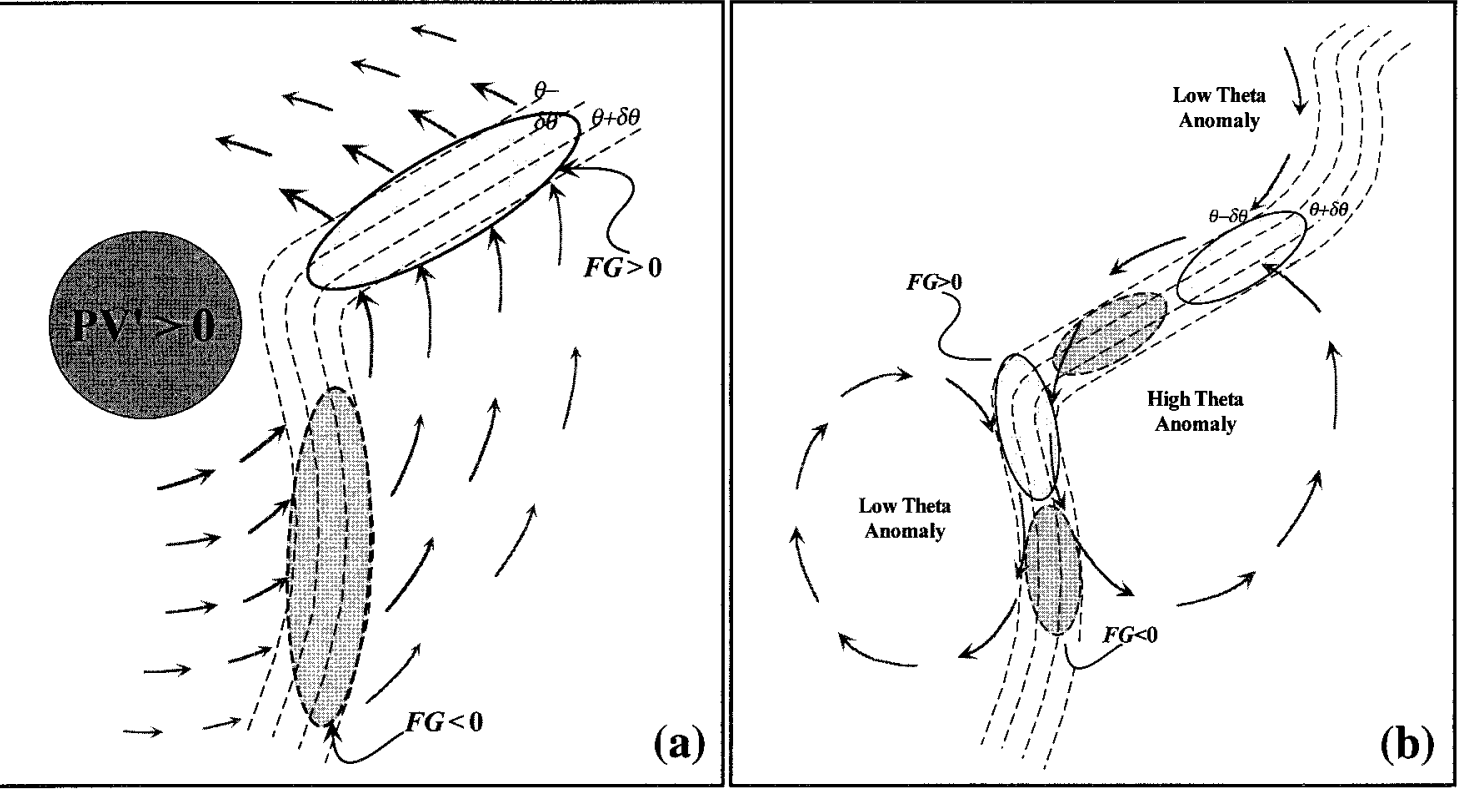

FIG. 3. (a) Schematic portrayal of the winds associated with an upper-tropospheric PV anomaly interacting with a mature surface thermal wave. Dashed lines are contours of surface potential temperature. Gray arrows represent $\mathbf{U}_{\text {pert }}$ winds at the surface. The light gray shaded ellipse, with a solid line border, represents the region where positive frontogenesis is forced by the $\mathbf{U}_{\text {pert }}$ winds. The light gray shaded ellipse, with a dashed line border, represents the region where negative frontogenesis is forced by the $\mathbf{U}_{\text {pert }}$ winds. The dark gray shaded circle represents the location of the upper-tropospheric PV anomaly. (b) Schematic portrayal of the circulation associated with a mature surface thermal trough-ridge pair interacting with the surface wave. Dashed lines are contours of surface potential temperature. Clockwise turning gray arrows represent the portion of the $\mathbf{S}_{\text {pert }}$ winds associated with the surface thermal trough. Counterclockwise turning gray arrows represent the portion of the $\mathbf{S}_{\text {pert }}$ winds associated with the surface thermal ridge. The light gray shaded ellipses, with a solid line border, represent regions where positive frontogenesis is forced by the $\mathbf{S}_{\text {pert }}$ winds. The light gray shaded ellipses, with a dashed line border, represent the regions where negative frontogenesis is forced by the $\mathbf{S}_{\text {pert }}$ winds.

whenever the relative humidity is greater than or equal to $70 \%$.

The combination of the three layers and their respective relative humidity criteria excludes only two parts of the total PV distribution from being inverted: 1) perturbation $P V$ in air with relative humidity less than $70 \%$ in the $800-700-\mathrm{hPa}$ layer, and 2) positive perturbation PV in air with relative humidity greater than or equal to $70 \%$ in the $400-50-\mathrm{hPa}$ layer. Careful scrutiny of the data revealed that the former portion of the total PV distribution was not significant in the present case. The latter portion of the total PV distribution is likely of little significance in most midlatitude storms and certainly was not important in this case. Finally, the potential double inversion of negative perturbation PV in air with relative humidity greater than or equal to $70 \%$ between 400 and $650 \mathrm{hPa}$ is avoided because such PV did not exist in this case. For the remainder of the paper $\mathbf{U}_{\text {pert }}$ will refer to the upper layer, $\mathbf{M}_{\text {pert }}$ will refer to the interior layer, and $\mathbf{S}_{\text {pert }}$ will refer to the surface layer.

The PV inversion steps described thus far recover only the nondivergent balanced flow. Isolating this portion of the flow can provide substantial insight into atmospheric processes. However, the remaining portion of the flow, namely the irrotational balanced wind and the unbalanced wind, are also important contributors to a cyclone's evolution. Therefore, a prognostic system of five equations is solved to obtain the irrotational balanced flow. This system, which consists of tendency equations for $\Phi, \psi$, and EPV, an omega equation, and a mass continuity equation, is presented in DE and solved in Davis et al. (1996). In contrast to Davis et al. (1996), moisture was not included when solving this system (see section 6). Thus, the sum of this irrotational balanced wind and the total nondivergent balanced wind represents all of the total flow that is recoverable through the implementation of the inversion technique described in this section. The remainder is the unrecoverable flow that contains the unbalanced flow (per Davis et al. 1996) as well as the balanced irrotational flow associated with latent heat release. We shall hereafter refer to this remainder as the unbalanced (unrecoverable) portion of the flow.

\section{b. Piecewise calculations of frontogenesis}

The idea of applying PV inversion results to study the evolution of mesoscale features, specifically fronts, was first suggested by Nielsen et al. (1991). Ramos (1997) was the first to use wind fields associated with PV anomalies to compute frontogenesis. He focused on 

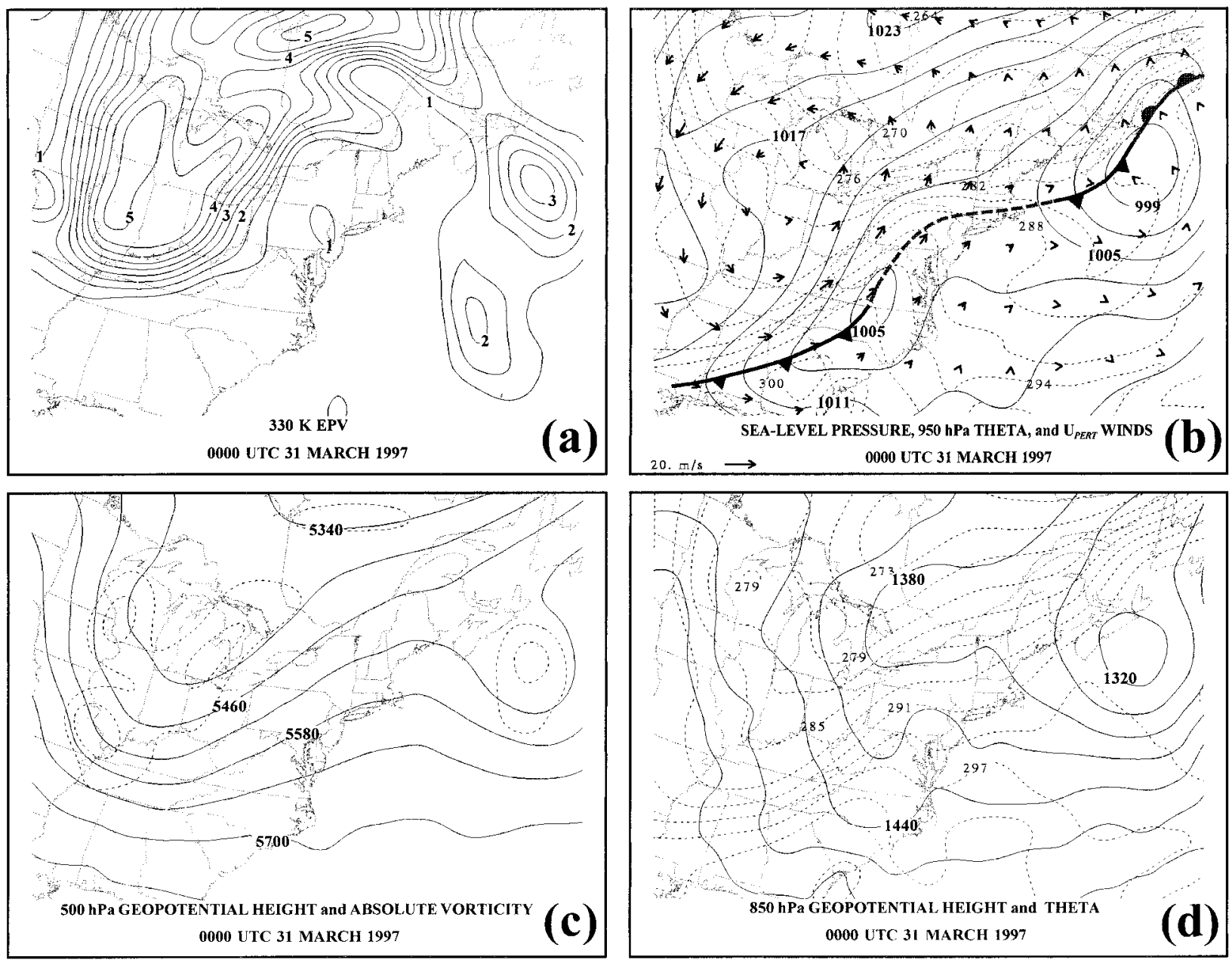

FIG. 4. (a) The 0-h forecast of PV on the 330-K isentropic surface, valid at 0000 UTC 31 Mar 1997, produced by the UW-NMS model simulation. Solid lines are contours of PV labeled in PV units (1 PVU $\left.=10^{-6} \mathrm{~m}^{2} \mathrm{~K} \mathrm{~kg}^{-1} \mathrm{~s}^{-1}\right)$ and contoured every $0.5 \mathrm{PVU}$, beginning at 1 PVU. (b) The 0-h forecast of sea level pressure, 950-hPa potential temperature, and 950-hPa $\mathbf{U}_{\text {pert }}$ winds, valid at 0000 UTC 31 Mar 1997, produced by the UW-NMS model simulation. Solid lines are contours of sea level pressure labeled in hPa and contoured every $3 \mathrm{hPa}$. Dashed lines are contours of potential temperature labeled in $\mathrm{K}$ and contoured every $3 \mathrm{~K}$. The $\mathbf{U}_{\text {pert }}$ wind is indicated by vectors. The $20 \mathrm{~m} \mathrm{~s}{ }^{-1}$ reference vector is given in the lower left. Conventional frontal symbols indicate positions of surface fronts with the dashed line indicating a surface trough. (c) The 0-h forecast of 500-hPa geopotential height and absolute vorticity, valid at 0000 UTC 31 Mar 1997, produced by the UW-NMS model simulation. Solid lines are contours of geopotential height labeled in $\mathrm{m}$ and contoured every $60 \mathrm{~m}$. Shading represents absolute vorticity contoured every $4 \times 10^{-5} \mathrm{~s}^{-1}$ starting with the $16 \times 10^{-5} \mathrm{~s}^{-1}$ contour. (d) The 00 -h forecast of 850 -hPa geopotential height and potential temperature, valid at 0000 UTC 31 Mar 1997, produced by the UW-NMS model simulation. Solid lines are contours of geopotential height labeled in $\mathrm{m}$ and contoured every $30 \mathrm{~m}$. Dashed lines are contours of potential temperature labeled in $\mathrm{K}$ and contoured every $3 \mathrm{~K}$.

the frontogenetical effects that discrete pieces of the PV distribution had on the formation of an upper front in an intense cyclone. More recently, Morgan (1999) has considered a similar partitioning of the frontogenesis. The ultimate goal of what we term piecewise frontogenesis is to determine which parts of the total flow exert controlling influences on the structure and evolution of fronts during all phases of cyclone development. Although the method can be applied at any level, in this paper we restrict our use of piecewise PV inversion results to examine aspects of the lower-tropospheric frontal evolution of the April Fools' Day storm.

Underlying the idea of piecewise frontogenesis is the fact that since the total wind can be partitioned into components associated with discrete PV anomalies, then so can the total frontogenesis. Of course, each PV anomaly has a perturbation $\theta$ distribution associated with it as well and, to be complete in the partitioning of frontogenesis, one would need to consider these associated $\theta$ anomalies separately. The more tenable approach of considering only the kinematic effects of the separate circulations on the total thermal field is taken here. From this perspective, computation of the frontogenesis forced by a portion of the total wind requires only that that portion of the wind be inserted into the Petterssen (1936) 2D frontogenesis equation 


$$
\begin{aligned}
\mathrm{F}_{2 \mathrm{D}} & =\frac{d}{d t}|\boldsymbol{\nabla} \theta| \\
& =\frac{1}{|\nabla \theta|}\left[-\frac{\partial \theta}{\partial x}\left(\frac{\partial u}{\partial x} \frac{\partial \theta}{\partial x}+\frac{\partial v}{\partial x} \frac{\partial \theta}{\partial y}\right)-\frac{\partial \theta}{\partial y}\left(\frac{\partial u}{\partial y} \frac{\partial \theta}{\partial x}+\frac{\partial v}{\partial y} \frac{\partial \theta}{\partial y}\right)\right] .
\end{aligned}
$$

The method chosen to partition the wind field in this study is illustrated in Fig. 2. From the piecewise PV perspective, the total wind can be broken down into the nondivergent portion of the balanced wind, the irrotational portion of the balanced wind, and a residual. The balanced wind refers to all that is recoverable from employing potential vorticity inversion, and the residual represents what is not recoverable. Davis et al. (1996) showed this residual is equal to the unbalanced component of the ageostrophic wind.

The nondivergent portion of the balanced flow can be further divided into the contributions from the $\mathbf{U}_{\text {pert }}$, $\mathbf{M}_{\text {pert }}, \mathbf{S}_{\text {pert }}$, mean, and neglected perturbation wind fields. The three perturbation winds are obtained from the piecewise part of the DE inversion method, while the mean wind is computed from the mean streamfunction. Our partitioning strategy for the piecewise inversion (section 3a) is designed to minimize the neglected PV perturbation and its associated winds. This partitioning implies that a discrete contribution to the total frontogenesis at any level resulting from the circulation associated with one of the three distinct "pieces" of PV can be determined. For example, the contribution to the total $950-\mathrm{hPa}$ frontogenesis made by the upper-level PV anomaly is calculated by substituting the $950-\mathrm{hPa} \mathbf{U}_{\text {pert }}$ winds and $950-\mathrm{hPa}$ potential temperature into (4). To compute the contribution to the total frontogenesis from the mean wind at any time, the mean wind and instantaneous potential temperature must be inserted into (4).

\section{c. Schematic examples}

Before looking at results from the 1 April case, it is useful to consider what factors will determine the frontogenetical effects of PV anomalies. Since the frontogenetical effects are a direct consequence of the circulations associated with the various PV anomalies, it is likely that the most important modulating factors are the strength of the PV anomaly, its penetration depth, and the orientation of the anomaly with respect to the baroclinic zone upon which it is acting. For example, consider an upper wave interacting with a mature surface thermal wave as portrayed schematically in Fig. 3a. It is clear that as the distance between the upper PV feature and the crest of the thermal wave decreases the magnitude of the $\mathbf{U}_{\text {pert }}$ winds at the surface will increase. The variation of the penetration depth across the surface baroclinic zones exerts a controlling influence on the resulting surface frontogenesis. Since the penetration depth is proportional to the static stability of an air column, the $\mathbf{U}_{\text {pert }}$ winds will be larger in the weakly stratified warm sector than in the colder air west of the cold front and poleward of the warm front. The resulting speed decrease and horizontal deformation across the warm front will force positive frontogenesis along that baroclinic zone, while the presumed speed increase and horizontal deformation across the cold front will force frontolysis there. The low-level frontogenesis resulting from such an interaction is highly sensitive to the geometry of the upper PV feature and its orientation to the low-level baroclinic zones. For instance, if the upper anomaly in Fig. 3a were cigar-shaped and parallel to the surface cold front zone, then little or no frontogenesis/frontolysis along that frontal zone would result.

Another interesting effect is produced by the interaction of the $\mathbf{S}_{\text {pert }}$ winds on the surface baroclinic zones. Consider a mature surface wave with a decaying upstream wave to its northeast and the circulations associated with them (Fig. $3 b)$. The thermal ridge in the developing wave has a cyclonic circulation associated with it, while the thermal troughs have anticyclonic circulations associated with them. The cold front of the growing disturbance lies in a region between two circulations, resulting in positive frontogenesis where confluence occurs in the northern portion of the cold front and frontolysis where diffluence occurs in the southern portion. The warm front of the growing storm also exhibits alternating regions of positive and negative frontogenesis associated with the $\mathbf{S}_{\text {pert }}$ directional changes across the zone and confluent flow associated with the low theta anomaly of the upstream cyclone. Surface baroclinic zones undergo considerable structural modification during the cyclone life cycle. The gross perturbation thermal structure, however, is not nearly as variable; the warm (cold) anomaly remains to the east (west) throughout the life cycle. Thus, the surface frontogenetic effect of the $\mathbf{S}_{\text {pert }}$ wind can be suprisingly invariant.

\section{Synoptic evolution}

One of the most memorable snowstorms in the history of southern New England occurred on 31 March-1 April 1997. The April Fools' Day storm, as it came to be known, brought record snowfalls and damaging winds to a large portion of the region. It was characterized by a strong upper PV anomaly, a significant interior PV anomaly associated with the record precipitation, and intense lowlevel baroclinic zones. The remainder of this section will provide a piecewise PV-based description of the synoptic evolution of these key features of this storm from 0000 UTC 31 March to 1200 UTC 1 April 1997.

\section{a. 0000 UTC 31 March 1997}

At 0000 UTC 31 March there were two significant features in the 330-K PV field (Fig. 4a). The 330-K surface intersected the isobaric surfaces from 240 to 340 hPa; thus, the PV shown in Fig. 4a is upper-tropospheric/lower-stratospheric PV. One significant feature was an isolated anomaly off the coast of Nova Scotia that 

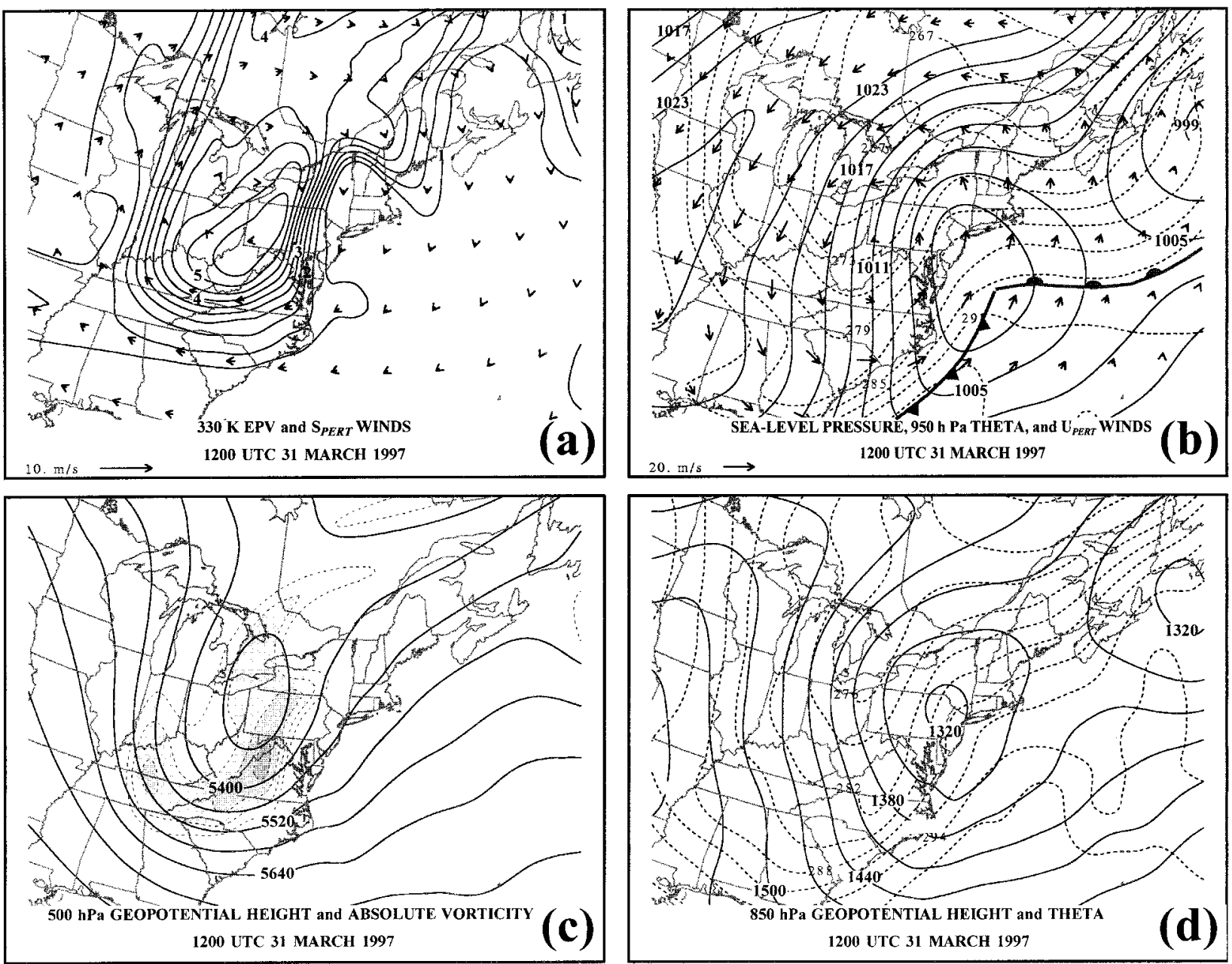

Fig. 5. (a) As for Fig. 4a except for 12-h forecast valid at 1200 UTC 31 Mar 1997. The $\mathbf{S}_{\text {pert }}$ wind on the 330-K isentropic surface is indicated by vectors. The $10 \mathrm{~m} \mathrm{~s}^{-1}$ reference vector is given in the lower left. (b) As for Fig. 4b except for 12-h forecast valid at $1200 \mathrm{UTC}$ 31 Mar 1997. (c) As for Fig. 4c except for 12-h forecast valid at 1200 UTC 31 Mar 1997. (d) As for Fig. 4d except for 12-h forecast valid at 1200 UTC 31 Mar 1997.

was associated with a decaying surface cyclone in the same location. The other important feature was a more substantial PV anomaly centered near Chicago. It was this latter feature that induced coastal cyclogenesis over the next $12 \mathrm{~h}$. There was no significant interior potential vorticity in the domain at this time.

At the surface (Fig. 4b) there were two waves in the potential temperature field, one just northeast of New York State and another over the mountains of North Carolina. It was this southernmost wave that evolved into the surface feature associated with the April Fools' Day cyclone. The diffuse temperature gradient in the Atlantic, off the Massachusetts coast, later developed into a significant warm front, and the moderate baroclinic zone that ran from western Pennsylvania to Alabama was later incorporated into the system as the primary cold front. In the sea level pressure field there was a dying cyclone in the Atlantic associated with the cutoff PV anomaly there and a very weak minimum over Virginia and North Carolina, which was associated with the potential temperature wave in that same region.

The upper-level PV features were reflected at $500 \mathrm{hPa}$ where there was a trough in the Atlantic directly above the Canadian cyclone, and a more substantial longwave trough over the Great Lakes, which had three shortwaves embedded within it. (Fig. 4c). Each of these waves was associated with a large-amplitude vorticity maximum. These $500-\mathrm{hPa}$ vorticity maxima correspond reasonably well to the PV anomalies observed on the $330-\mathrm{K}$ surface. At $850 \mathrm{hPa}$ there was a weak trough in the height field over the Appalachian Mountains, while the lower-tropospheric baroclinic zones were clearly defined (Fig. 4d).

The winds associated with the upper PV anomaly over Chicago were already influencing the surface baroclinic zone by this time (Fig. 4b). The axis of maximum winds, at the surface, was located just upstream of the axis of maximum $\theta$ in Virginia and North Carolina. Thus, at this time, the upper anomaly was acting to retard the eastward 

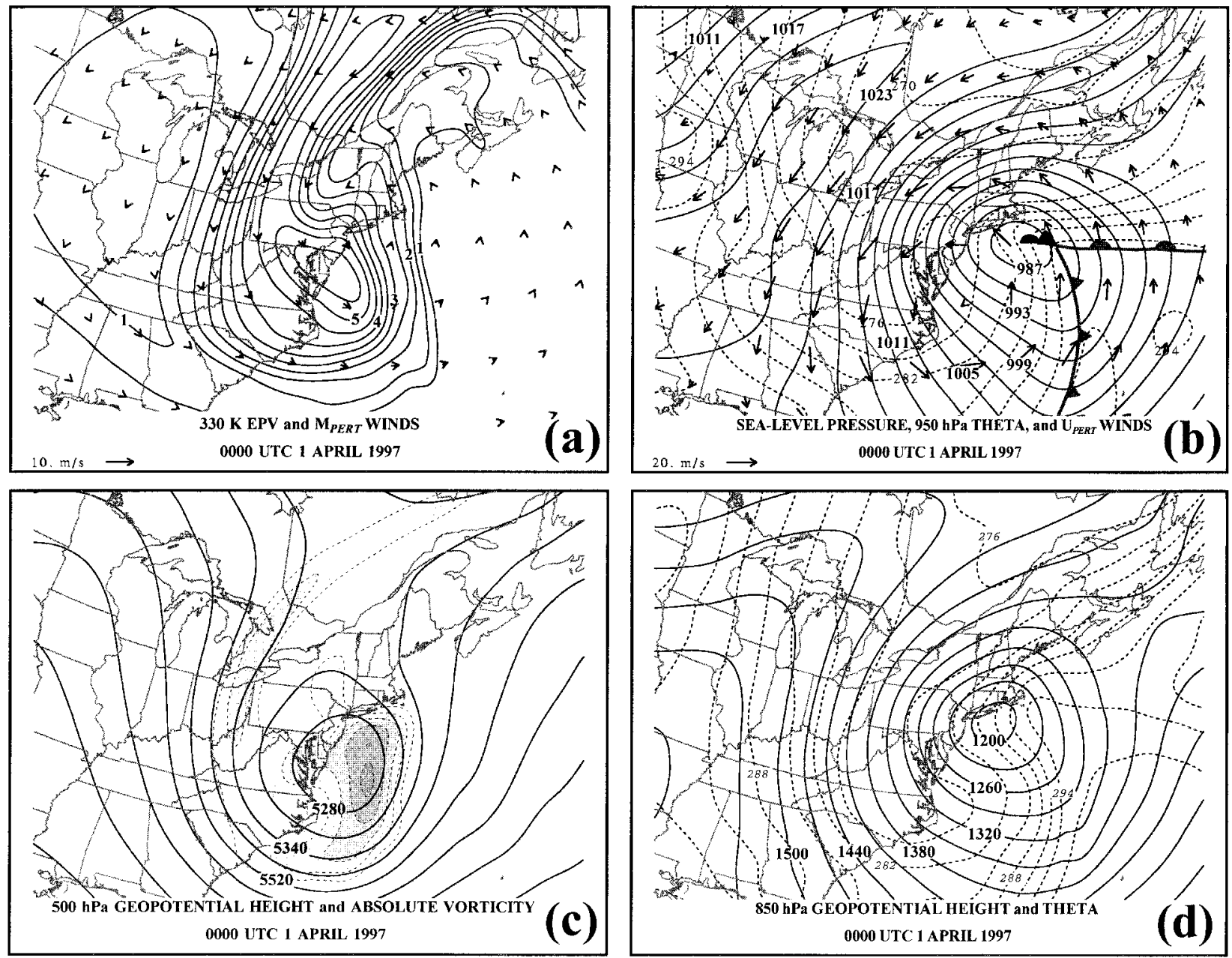

FIG. 6. (a) As for Fig. 4a except for 24-h forecast valid at 0000 UTC 1 Apr 1997. The $\mathbf{M}_{\text {pert }}$ wind on the 330-K isentropic surface is indicated by vectors. The $20 \mathrm{~m} \mathrm{~s}^{-1}$ reference vector is given in the lower left. (b) As for Fig. 4b except for 24-h forecast valid at $0000 \mathrm{UTC}$ 1 Apr 1997. (c) As for Fig. 4c except for 24-h forecast valid at 0000 UTC 1 Apr 1997. (d) As for Fig. 4d except for 24-h forecast valid at 0000 UTC 1 Apr 1997.

propagation of the surface thermal wave while simultaneously amplifying it. In response to this forcing the sea level pressure minimum deepened slightly and moved slowly to the northeast over the next $12 \mathrm{~h}$. Such behavior is in line with expectations for a cyclogenesis event in which an upper PV anomaly gradually encroaches upon a low-level baroclinic zone, amplifying the surface wave (producing a cyclone) as it does so. This interaction was modest until after 1200 UTC 31 March, by which time the decreased distance between the surface wave and upper PV anomaly led to rapid cyclogenesis.

\section{b. 1200 UTC 31 March 1997}

By 1200 UTC 31 March the upper PV anomaly, formerly located near Chicago, had been advected to the southeast and intensified slightly (Fig. 5a). At the surface (Fig. 5b), the baroclinic zones were becoming better organized, with the cold front moving just off the southeast coast of the United States and the warm front intensifying to the northeast. Also, there was a suggestion of secondary cold front development in central New York and Pennsylvania. The sea level pressure minimum had deepened slightly to $999 \mathrm{hPa}$, and it was now situated off the Delaware coast. The winds associated with the upper PV anomaly were acting to intensify (amplify) the surface potential temperature wave at this time. There was no evidence of two-way interaction occurring however, as the cyclonic winds from the surface wave were not amplifying the upper PV wave (Fig. 5a). Instead the $\mathbf{S}_{\text {pert }}$ wind field was dominated by the largescale potential temperature trough to the west, which was associated with an anticyclonic circulation centered over southeast Ontario. This circulation was actually retarding the eastward propagation of the upper PV anomaly. This circumstance allowed for a longer period of favorable interaction between the upper PV anomaly and the surface wave. Light precipitation had begun, 

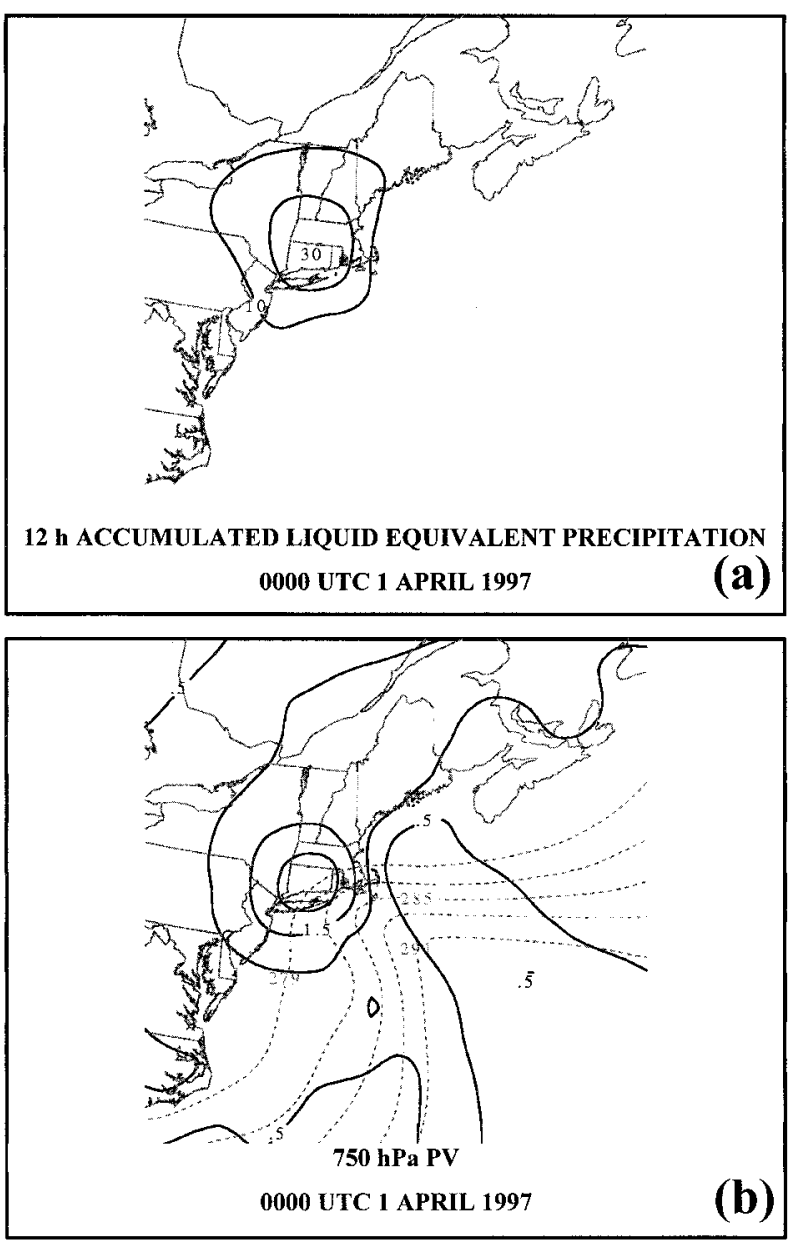

FIG. 7. (a) The 12-h accumulated liquid-equivalent precipitation, valid at 0000 UTC 1 Apr 1997, produced by the UW-NMS model simulation. Solid lines are contours of liquid-equivalent precipitation contoured every $10 \mathrm{~mm}$, beginning at $10 \mathrm{~mm}$. The convective precipitation along the cold front is not shown. (b) The 24-h forecast of 750hPa PV, valid at 0000 UTC 1 Apr 1997, produced by the UW-NMS model simulation. Solid lines are contours of PV labeled in PVU and contoured every 0.5 PVU, beginning at 0.5 PVU. Dashed gray lines are contours of $950-\mathrm{hPa}$ potential temperature labeled in $\mathrm{K}$ and contoured every $3 \mathrm{~K}$, beginning at $279 \mathrm{~K}$ and ending at $291 \mathrm{~K}$.

with rain along the New England coast and snow at the higher elevations (not shown), but there was still no substantial interior PV.

The trough in the $500-\mathrm{hPa}$ height field followed the same path as the upper PV anomaly while deepening (Fig. 5c). At $850 \mathrm{hPa}$ a well-defined minimum in the geopotential height field had developed, centered over northeast Pennsylvania, and the frontal zones had intensified during the 12-h period (Fig. 5d). The baroclinic zones at $850 \mathrm{hPa}$ were clearly vertical extensions of the surface warm and cold fronts.

\section{c. 0000 UTC 1 April 1997}

By 0000 UTC 1 April the upper PV anomaly had moved farther to the southeast and was centered over

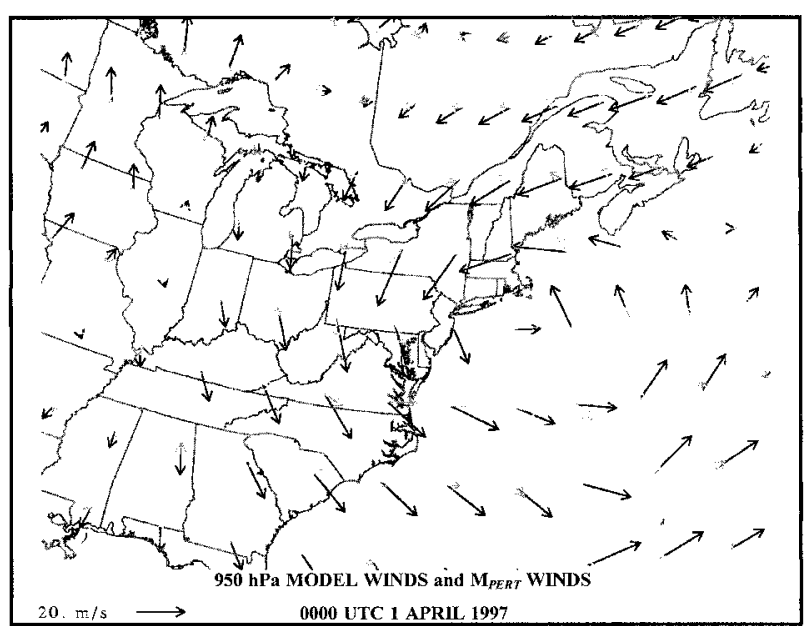

FIG. 8. The 24-h forecast of 950-hPa total model winds and 950-hPa $\mathbf{M}_{\text {pert }}$ winds, valid at 0000 UTC 1 Apr 1997. Total model wind is indicated by black vectors. The $\mathbf{M}_{\text {pert }}$ wind is indicated by gray vectors. The $20 \mathrm{~m} \mathrm{~s}^{-1}$ reference vector, valid for both wind fields, is given in the lower left.

Washington, D.C. By this time it had begun to deform into what Martin (1998) referred to as a "treble clef", (Fig. 6a). The appearance of the treble clef shape in the 330-K PV implies that an occluded thermal structure was beginning to develop in the lower troposphere. The sea level pressure minimum had fallen to $984 \mathrm{hPa}$ and the minimum moved slightly to the northeast, centered just southeast of Block Island, Rhode Island (Fig. 6b), at this time. The sea level pressure gradient was very strong to the north and west of the cyclone center, leading to blizzard conditions over much of southern New England. The surface potential temperature wave developed in step with the surface cyclone and was a robust feature by this time. The circulation associated with the upper PV anomaly was still forcing the amplification of this feature. Also, the thermal wave's propagation to the northeast was a result of the winds associated with the wave acting upon itself, the normal Rossby wave propagation mechanism (not shown)what HMR refer to as "self-propagation."

The fronts associated with the surface wave continued to evolve over this 12 -h interval. The warm front intensified dramatically and the cold front moved much farther eastward into the Atlantic. The intensity of the surface cold front had diminished as it moved out over the warmer water, but it was still quite strong at 850 hPa (Fig. 6d). At this level, a more traditional occluded structure was evident, consistent with the development of the treble clef shape in the upper PV.

The 850- and 500-hPa minima in geopotential height also moved to the southeast, and by this time they were almost collocated, with the $850-\mathrm{hPa}$ low over the sea level pressure minimum and the $500-\mathrm{hPa}$ low just to its southwest (Figs. 6c,d). However, the surface low center and $850-\mathrm{hPa}$ geopotential minimum were both to the 

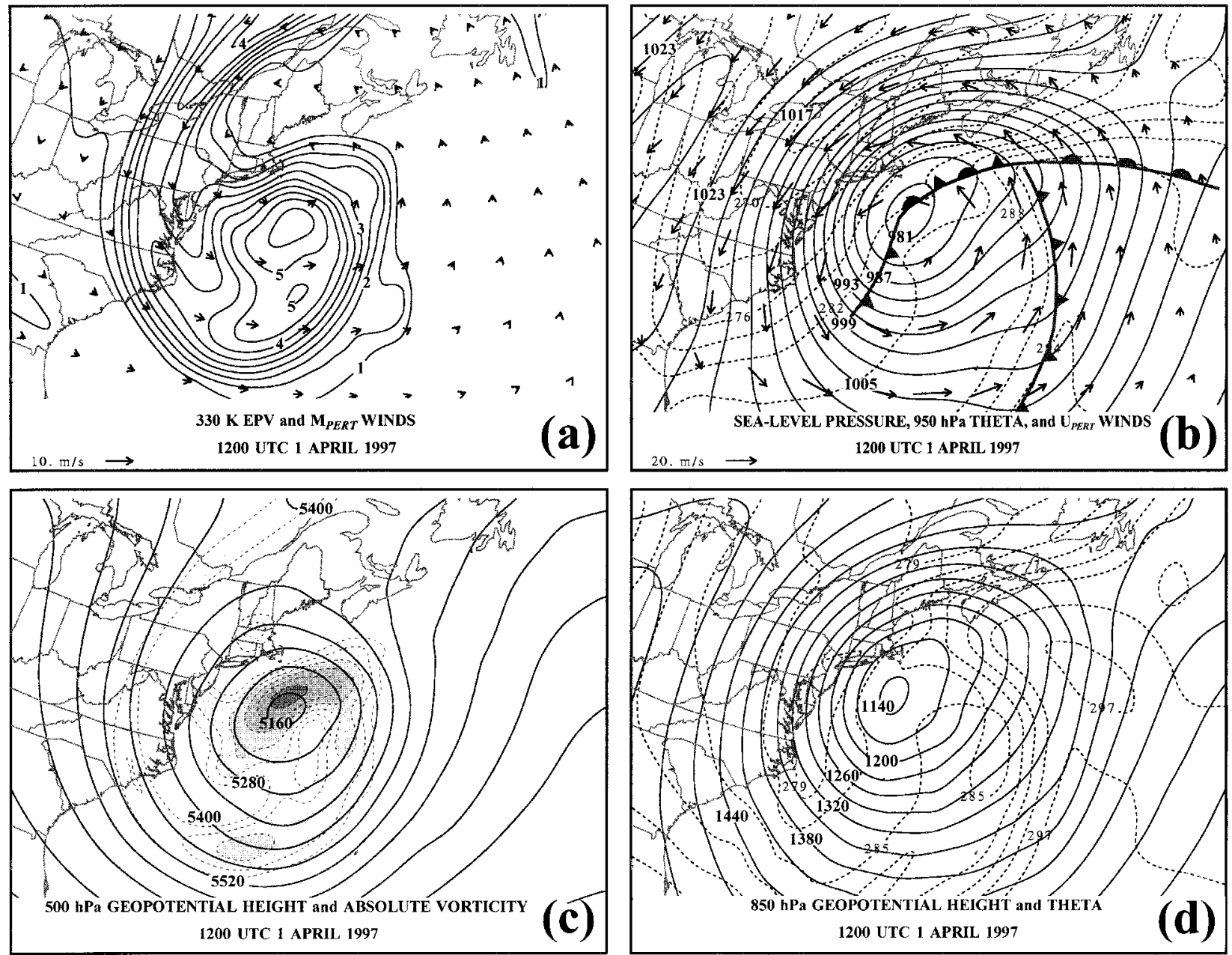

FIG. 9. (a) As for Fig. 4a except for 36-h forecast valid at 1200 UTC 1 Apr 1997. The $\mathbf{M}_{\text {pert }}$ wind on the 330-K isentropic surface is indicated by vectors. The $20 \mathrm{~m} \mathrm{~s}^{-1}$ reference vector is given in the lower left. (b) As for Fig. 4b except for 36-h forecast valid at 1200 UTC 1 Apr 1997. (c) As for Fig. 4c except for 36-h forecast valid at 1200 UTC 1 Apr 1997. (d) As for Fig. 4d except for 36-h forecast valid at 1200 UTC 1 Apr 1997

northeast of the upper PV anomaly, suggesting further development was likely.

As the cyclogenesis ensued, significant precipitation developed along the intensifying frontal zones. Of particular interest in this discussion was the blossoming heavy snow in southern New England (Fig. 7a). This, in turn, led to the development of a substantial interior PV anomaly (Fig. 7b), located directly above the band of maximum precipitation in southern New England. This feature was almost collocated with the surface potential temperature wave, situated just to the southeast. Thus, the cyclonic circulation associated with the interior PV was contributing constructively to the total surface circulation (Fig. 8). The $\mathbf{M}_{\text {pert }}$ winds also influenced the morphological evolution of the upper PV anomaly, by advecting high PV to the north and east (off the mid-Atlantic and southern New England coasts) and low PV to the west and southwest (over southern Quebec and central New York) (Fig. 6a).

\section{d. 1200 UTC 1 April 1997}

By 1200 UTC the upper-level PV anomaly was almost cutoff and its center had moved northeastward to a position southeast of Cape Cod (Fig. 9a). The treble clef shape of the upper PV was now fully developed and was reflected in the occluded thermal structure present in the underlying troposphere (Fig. 9d).

The sea level pressure minimum had moved only slightly but had deepened to $980 \mathrm{hPa}$, even though the original surface potential temperature wave had not undergone further amplification (Fig. 9b). The wave continued to propagate to the northeast, which resulted in the cold front moving far into the Atlantic, while the warm front edged closer to the coast of Nova Scotia. The cold front decreased in intensity and the warm front intensified, with the $\mathbf{U}_{\text {pert }}$ winds (Fig. 9b) providing some of the forcing for the frontogenesis along the warm front. The result of these changes at the surface was 

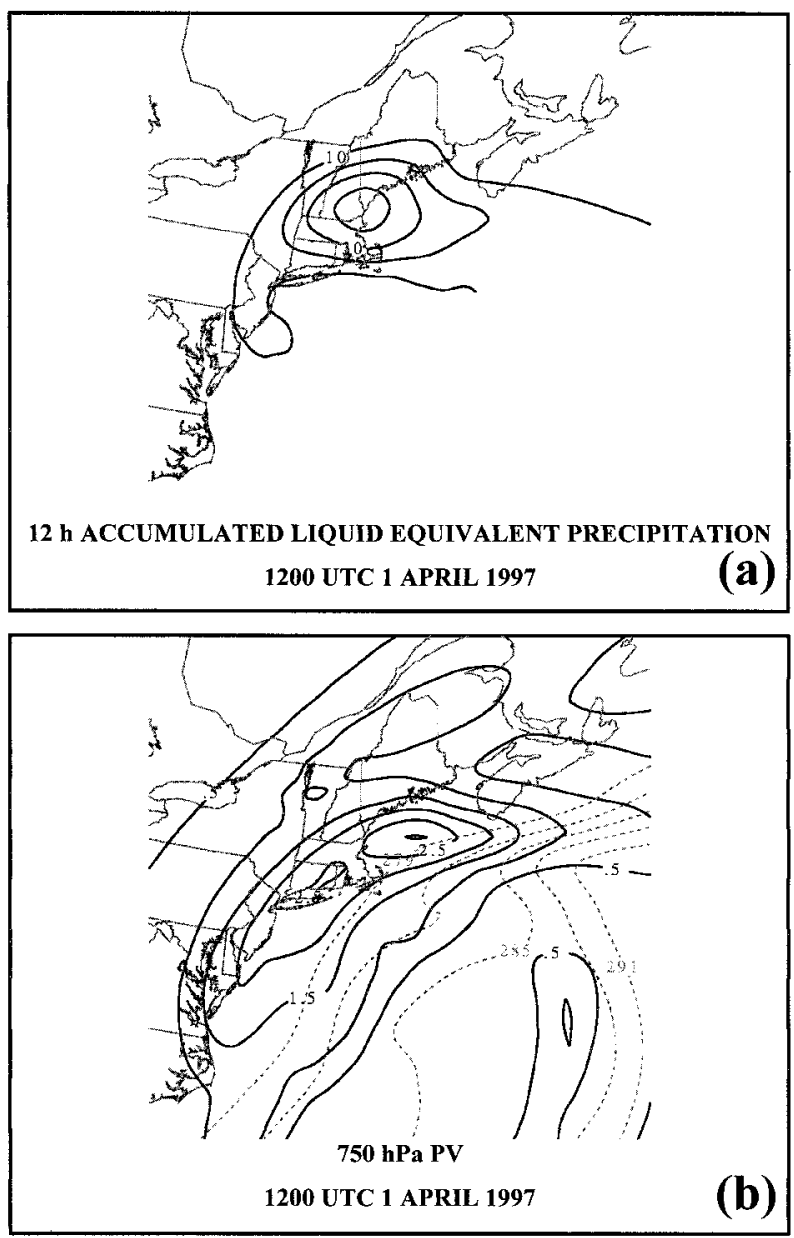

FIG. 10. (a) As for Fig. 7a except for 36-h forecast valid at 1200 UTC 1 Apr 1997. (b) As for Fig. 7b except for 36-h forecast valid at 1200 UTC 1 Apr 1997.

that, by this time, the frontal structure had taken on a robust T-bone shape, with an intense warm front, an occluded front, a cold front significantly removed from the low center, and a bent-back front trailing along the coast. The sea level pressure minimum was no longer associated with the original thermal wave. Instead it was loosely associated with the broader surface potential temperature wave, which was composed of the intense warm front and its bent-back extension.

Figures 9c and 9d demonstrate that the 500- and 850$\mathrm{hPa}$ geopotential height minima were collocated by this time, as a result of the lack of movement by the 850 $\mathrm{hPa}$ low and the northeastward movement of the 500$\mathrm{hPa}$ low. The multiple waves at the tropopause are fairly well reflected in the 500-hPa vorticity field. The $850-$ $\mathrm{hPa}$ potential temperature field reflected the surface warm and cold fronts, but a more traditional occluded structure existed at this level than at the surface. The secondary cold front does not appear at $850 \mathrm{hPa}$, testifying to its shallow nature.

Heavy precipitation had occurred in the $12 \mathrm{~h}$ leading

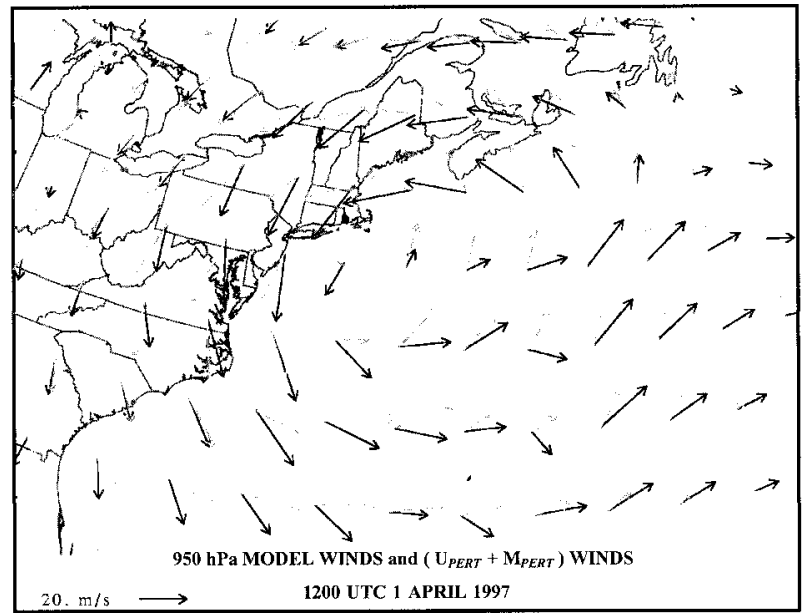

FIG. 11. The 36-h forecast of 950-hPa total model winds and the sum of 950-hPa $\mathbf{M}_{\text {pert }}$ and $\mathbf{U}_{\text {pert }}$ winds, valid at 1200 UTC 1 Apr 1997. Total model wind is indicated by black vectors. The sum of $\mathbf{M}_{\mathrm{pert}}$ and $\mathbf{U}_{\text {pert }}$ winds is indicated by gray vectors. The $20 \mathrm{~m} \mathrm{~s}^{-1}$ reference vector, valid for both wind fields, is given in the lower left.

up to 1200 UTC 1 April in the form of snow inland and rain just off the coast of Maine (Fig. 10a). Accordingly, a considerable intensification of the interior PV anomaly that appeared $12 \mathrm{~h}$ earlier (Fig. 10b) had occurred by this time. The intensified interior PV anomaly was centered just southeast of the Maine coast and stretched far to the southwest, with a maximum intensity of over 3 PVU. The circulation associated with this feature, along with the circulation associated with the upper anomaly, contributed substantially to the total surface winds (Fig. 11), which helped to maintain the surface low pressure center even though the primary surface thermal wave had propagated away to the northeast. The $\mathbf{M}_{\text {pert }}$ winds continued to exact an influence on the evolution of the 330-K PV anomalies (Fig. 9a) by advecting high PV to the north and east on the eastern side of the treble clef (in the Gulf of Maine and south of Nova Scotia) while advecting low PV to the south in the notch of the treble clef (in central New England, New York, and the middle Atlantic states).

\section{Piecewise frontogenesis in the 1 April storm}

A comprehensive examination of the frontal evolution observed in the April Fools' Day storm is beyond the scope of this paper. Instead, we focus primarily on the warm and bent-back fronts and their evolutions over an 18-h period from 1800 UTC 31 March to 1200 UTC 1 April. It was during this period that the cyclone reached maximum intensity, dropped heavy snow in southern New England, and became deeply occluded.

\section{a. 1800 UTC 31 March}

In section 4 it was shown that an intense warm front developed from a weak stationary front in the Atlantic, 

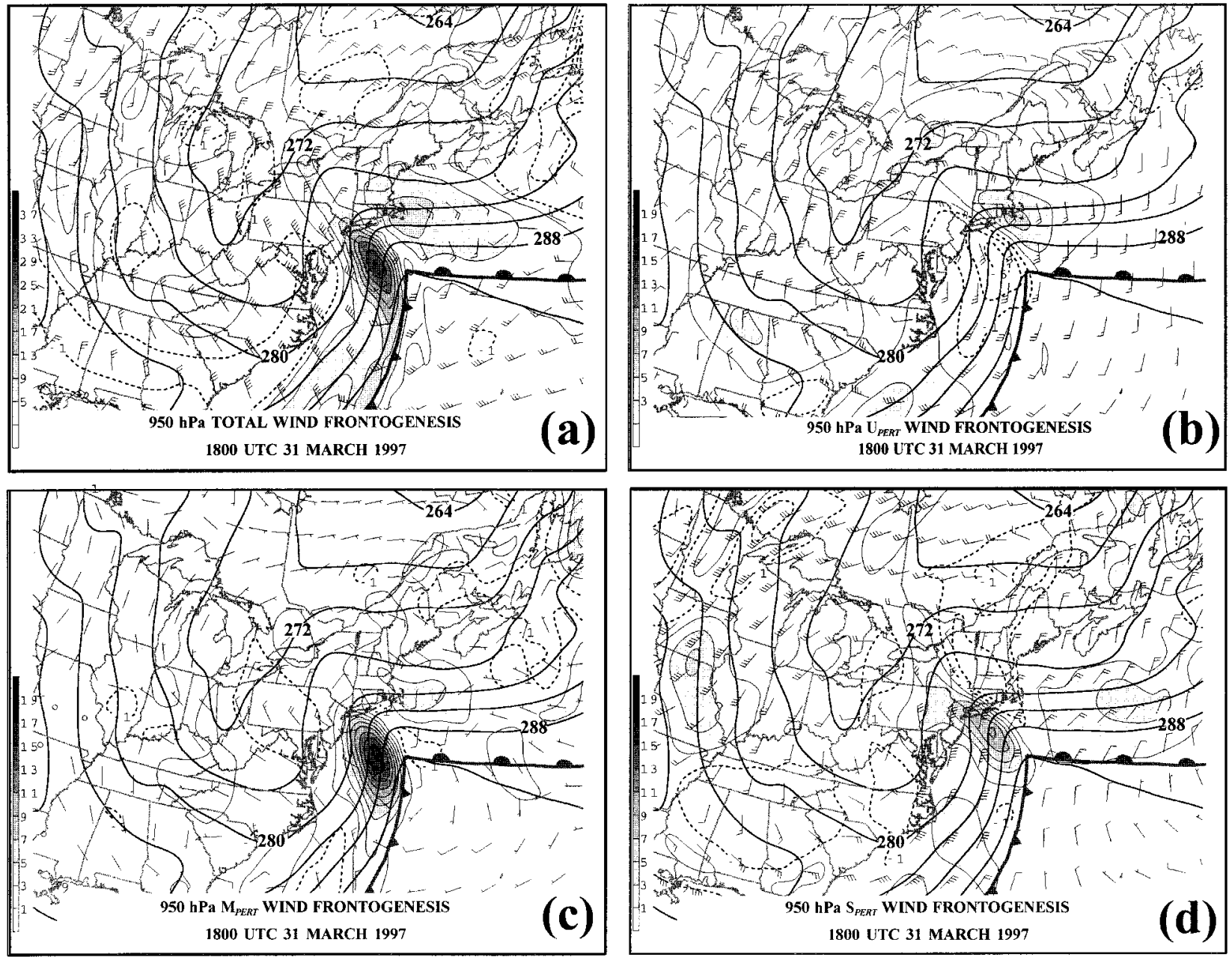

FIG. 12. (a) The 18 -h forecast of $950-\mathrm{hPa} 2 \mathrm{D}$ frontogenesis forced by the total model wind, valid at 1800 UTC 31 Mar. Shading represents positive frontogenesis contoured every 4 frontogenesis units (FGU) beginning at 1 FGU [1 FGU $\left.=10 \mathrm{~K}(100 \mathrm{~km})^{-1}(3 \mathrm{~h})^{-1}\right]$, with legend in the lower left. Dashed lines are contours of negative frontogenesis contoured every 4 FGU beginning at -1 FGU. Solid lines are contours of 950-hPa potential temperature labeled in $\mathrm{K}$ and contoured every $4 \mathrm{~K}$. Conventional frontal symbols indicate the position of surface fronts. The barbs represent the total wind. Wind speeds are indicated by a circle, calm; line with no barb, $<2.5 \mathrm{~m} \mathrm{~s}^{-1}$; short barb, $2.5 \mathrm{~m} \mathrm{~s}{ }^{-1}$; long barb, $5 \mathrm{~m} \mathrm{~s}^{-1}$; and flag, $25 \mathrm{~m} \mathrm{~s}^{-1}$. (b) The 18-h forecast of 950-hPa 2D frontogenesis forced by the $\mathbf{U}_{\text {pert }}$ winds, valid at 1800 UTC 31 Mar. Shading represents positive frontogenesis contoured every 2 FGU beginning at 1 FGU, with legend in the lower left. Dashed lines are contours of negative frontogenesis contoured every 2 FGU beginning at -1 FGU. Solid lines are contours of 950-hPa potential temperature labeled and contoured as in (a). The barbs represent the $\mathbf{U}_{\text {pert }}$ wind. Wind speeds are indicated as in (a). (c) As for (b) except for 950-hPa 2D frontogenesis forced by the $\mathbf{M}_{\text {pert }}$ winds. Wind barbs represent the $\mathbf{M}_{\text {ert }}$ wind and are indicated as in (a). (d) As for (b) except for 950$\mathrm{hPa} 2 \mathrm{D}$ frontogenesis forced by the $\mathbf{S}_{\text {pert }}$ winds. Wind barbs represent the $\mathbf{S}_{\text {pert }}$ wind and are indicated as in (a).

with most of the intensification occurring after 1200 UTC 31 March. This warm front was a significant feature in the April Fools' Day storm as the vertical circulation associated with it produced much of the record precipitation, which in turn led to the formation of the interior PV anomaly. The frontogenesis southeast of New England, forced by the total wind at 1800 UTC 31 March (Fig. 12a), confirms that the intensification of the warm front had begun by this time. The modest frontogenesis along the warm front was primarily the result of the $\mathbf{U}_{\text {pert }}$ (Fig. 12b) wind field with more modest contributions from the $\mathbf{M}_{\text {pert }}$ (Fig. 12c) and $\mathbf{S}_{\text {pert }}$ (Fig. $12 \mathrm{~d}$ ) wind fields. The $\mathbf{U}_{\text {pert }}$ winds forced a concentrated area of frontogenesis centered over Cape Cod, Massachusetts, but extending through central New England into southern Quebec. The influence of the $\mathbf{M}_{\text {pert }}$ winds was confined to a smaller subset of this region. The $\mathbf{S}_{\text {pert }}$ wind (Fig. 12d) contribution to the intensification of the warm front was concentrated in a broad area south of Nova Scotia at this time. A small contribution to warm frontal intensification was made by the mean winds at this time (Fig. 12e). A modest contribution was also made by the irrotational balanced winds (Fig. 12f). In fact, the warm frontogenesis forced by the total balanced wind (the sum of the $\mathbf{U}_{\text {pert }}, \mathbf{M}_{\text {pert }}, \mathbf{S}_{\text {pert }}$, mean, and irrotational balanced winds) (Fig. 12g) accounted for nearly 

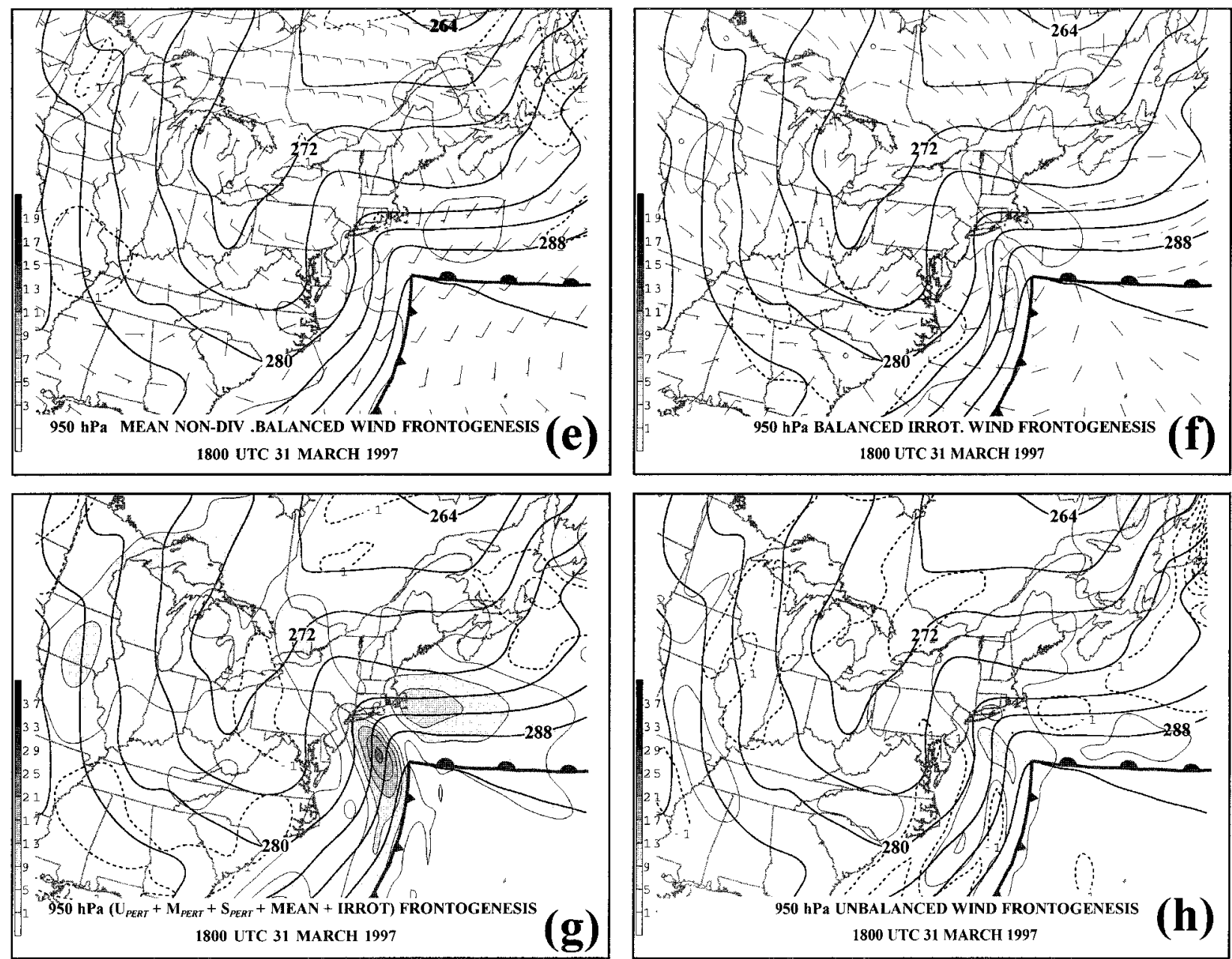

FIG. 12. (Continued) (e) As for (b) except for $950-\mathrm{hPa} 2 \mathrm{D}$ frontogenesis forced by the mean nondivergent balanced wind. Wind barbs represent the mean nondivergent balanced wind and are indicated as in (a). (f) As for (a) except for 950-hPa 2D frontogenesis forced by the balanced irrotational wind (IRROT). Wind barbs represent the total nondivergent wind and are indicated as in (a). (g) The 18-h forecast of $950-\mathrm{hPa} 2 \mathrm{D}$ frontogenesis forced by the sum of the $\mathbf{U}_{\text {pert }}, \mathbf{M}_{\text {pert }}, \mathbf{S}_{\text {pert }}$, IRROT, and mean nondivergent balanced winds, valid at 1800 UTC 31 Mar. Shading represents positive frontogenesis contoured every 4 FGU beginning at 1 FGU, with legend in the lower left. Dashed lines are contours of negative frontogenesis contoured every 4 FGU beginning at -1 FGU. Solid lines are contours of 950 -hPa potential temperature labeled and contoured as in (a). (h) The 18-h forecast of $950-\mathrm{hPa} 2 \mathrm{D}$ frontogenesis forced by the unbalanced wind (a)-(g). Shading represents positive frontogenesis contoured every 4 FGU beginning at 1 FGU, with legend in the lower left. Dashed lines are contours of negative frontogenesis contoured every 4 FGU beginning at -1 FGU. Solid lines are contours of $950 \mathrm{hPa}$ potential temperature labeled and contoured as in (a).

all of the frontogenesis forced by the total wind (Fig. $12 \mathrm{a})$.

The irretrievable or unbalanced frontogenesis, defined as the difference between the total frontogenesis and the total balanced frontogenesis, is shown in Fig. 12h. It is interesting to note that the intense frontogenesis located along the northern portion of the cold frontal zone (on the southwestern edge of the thermal ridge) was also predominantly a result of frontogenesis by the balanced flow. The domain-wide smallness of the unbalanced frontogenesis suggests that, at this early point in the cyclone life cycle, the frontogenesis associated with the unbalanced portion of the flow was not significant.

\section{b. 0000 UTC 1 April}

By 0000 UTC 1 April, the warm front had intensified substantially and strong frontogenetical forcing by the total wind was occurring off of the southern New England coast (Fig. 13a). The winds associated with the upper and interior PV anomalies were still the major nondivergent contributors to this frontogenesis (Figs. $13 \mathrm{~b}, \mathrm{c})$, with the primary contribution coming from the $\mathbf{U}_{\text {pert }}$ winds. Again, the frontogenesis by the $\mathbf{U}_{\text {pert }}$ winds covered a larger area (stretching from the Bay of Fundy, over all of New England, and southward to New Jersey), while the frontogenesis by the $\mathbf{M}_{\text {pert }}$ winds was strewn 

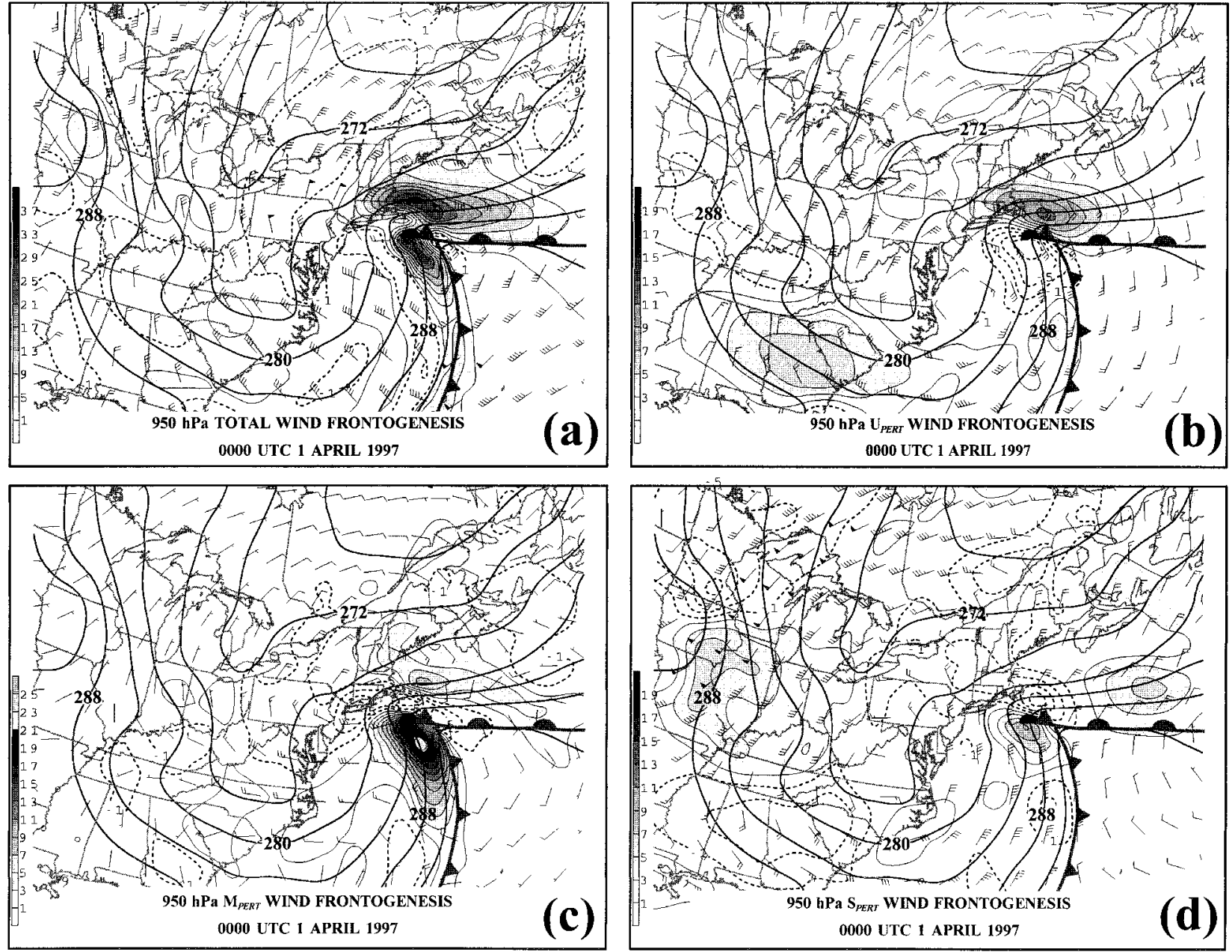

FIG. 13. (a) As for Fig. 12a except for 24-h forecast valid at 0000 UTC 1 Apr 1997. (b) As for Fig. 12b except for 24-h forecast valid at 0000 UTC 1 Apr 1997. (c) As for Fig. 12c except for 24-h forecast valid at 0000 UTC 1 Apr 1997. (d) As for Fig. 12d except for 24-h forecast valid at 0000 UTC 1 Apr 1997. (e) As for (a) except for 24-h forecast of total nondivergent wind frontogenesis valid at 0000 UTC 1 Apr 1997. (f) As for Fig. $12 \mathrm{f}$ except for 24-h forecast valid at 0000 UTC 1 Apr 1997. (g) As for Fig. 12h except for 24-h forecast valid at 0000 UTC 1 Apr 1997.

along the length of the warm front and into central New England. The warm frontogenesis associated with the $\mathbf{U}_{\text {pert }}$ winds was a result of both a decrease in wind speed across the front (as suggested schematically in Fig. 3a) as well as cyclonic shear across the front (a consequence of the continued development of the upper vortex). The warm frontogenesis forced by the $\mathbf{S}_{\text {pert }}$ winds was modest and concentrated on the eastern portion of the warm front (Fig. 13d). The distribution of frontogenesis/frontolysis forced by the $\mathbf{S}_{\text {pert }}$ winds resembled the pattern depicted schematically in Fig. 3b. A visual inspection of the $\mathbf{S}_{\text {pert }}$ winds confirms that confluence was forcing the frontogenesis along the warm front and on the southern edge of the crest of the thermal wave, while diffluence was forcing the frontolysis along the cold front. Confluent flow in the western portion of the warm front acted frontolytically for two reasons. First, the isentropes were oriented perpendicular to the axis of dila- tation; and second, the largest wind speeds were south of the warm frontal baroclinic zone.

Once again, the mean winds (not shown) did not contribute significantly to the intensification of the warm front. By this time, however, the total wind frontogenesis (Fig. 13a) exceeded the nondivergent balanced frontogenesis (Fig. 13e) by a considerable amount in the developing warm frontal region. The contribution of the irrotational balanced frontogenesis makes up roughly $25 \%$ of the difference between the two (Fig. 13f). Thus, the frontogenesis by the unbalanced flow (Fig. 13g) had become a significant contributor to warm frontogenesis by 0000 UTC 1 April. Although the balanced flow frontogenesis differed from the total near the cold front as well (the frontolysis west and frontogenesis east of the front were underestimated) the differences were much larger in association with the warm front at this time. 

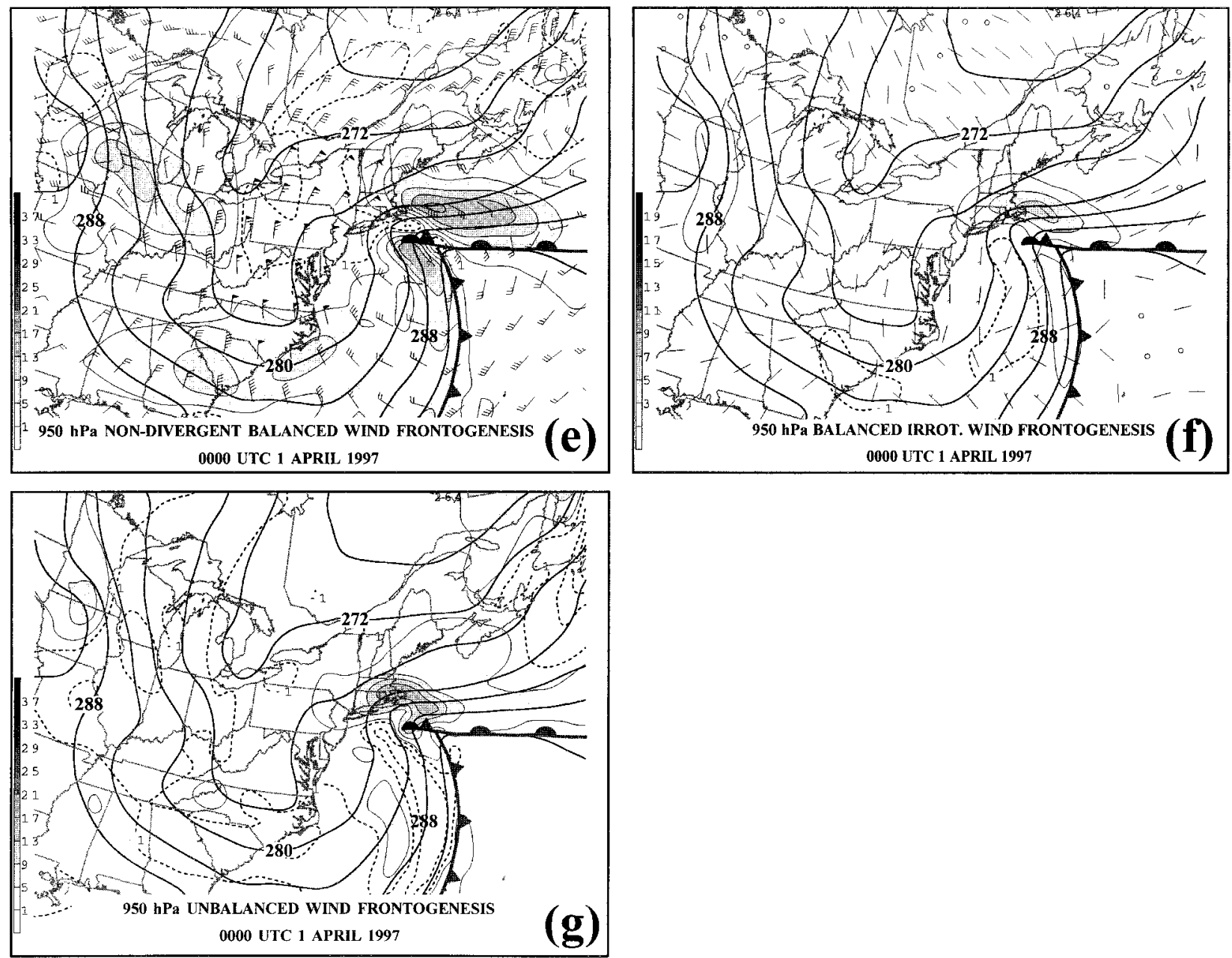

FIG. 13. (Continued)

\section{c. 0600 UTC 1 April}

Six hours later at 0600 UTC 1 April the distribution of frontogenesis by the total wind along the warm front had changed subtly (Fig. 14a). There was a hint of frontolysis in the crest of the thermal wave bordered by a frontogenesis axis to its west along a developing bentback extension to the warm front. Despite these changes, the sources for the nondivergent balanced frontogenesis along the warm front had not changed. The frontogenesis associated with the $\mathbf{U}_{\text {pert }}$ and $\mathbf{M}_{\text {pert }}$ winds (Figs. $14 \mathrm{~b}, \mathrm{c})$ continued to account for most of the nondivergent balanced frontogenesis along the warm front. The $\mathbf{U}_{\text {pert }}$ wind frontogenesis was the most significant contributor and covered a large area, extending along the entire warm front from south of the Canadian Maritime Provinces southwestward to the New Jersey coast. The $\mathbf{M}_{\text {pert }}$ wind frontogenesis was weaker and concentrated farther east than the maximum $\mathbf{U}_{\text {pert }}$ frontogenesis. Note that the $\mathbf{M}_{\text {pert }}$ winds were also forcing significant frontolysis along the extreme western portion of the warm front and along the entire length of its bent-back extension.
The frontogenesis forced by the $\mathbf{S}_{\text {pert }}$ winds (Fig. 14d) continued to be a factor along the eastern periphery of the warm front. The distribution of $\mathbf{S}_{\text {pert }}$ frontogenesis remained well described by the schematic portrayed in Fig. 3b.

The total wind frontogenesis exceeded the total nondivergent balanced frontogenesis along the warm front and, more notably, along the bent-back front at this time (Fig. 14e). A fraction of the difference was made up by the irrotational balanced frontogenesis, which captured some of the intensification of the bent-back extension to the warm front (Fig. 14f). The irrotational balanced winds reflect some of the convergence associated with the extreme precipitation that was affecting southern New England at this time. It is interesting to note that the total balanced wind (Figs. 14e and 14f combined) accounted for most of the large frontogenesis at the northern end of the cold front at this time.

The unbalanced frontogenesis at 0600 UTC is shown in Fig. 14g. Two features are notable in this field. First, the magnitudes of the unbalanced frontogenesis in the 

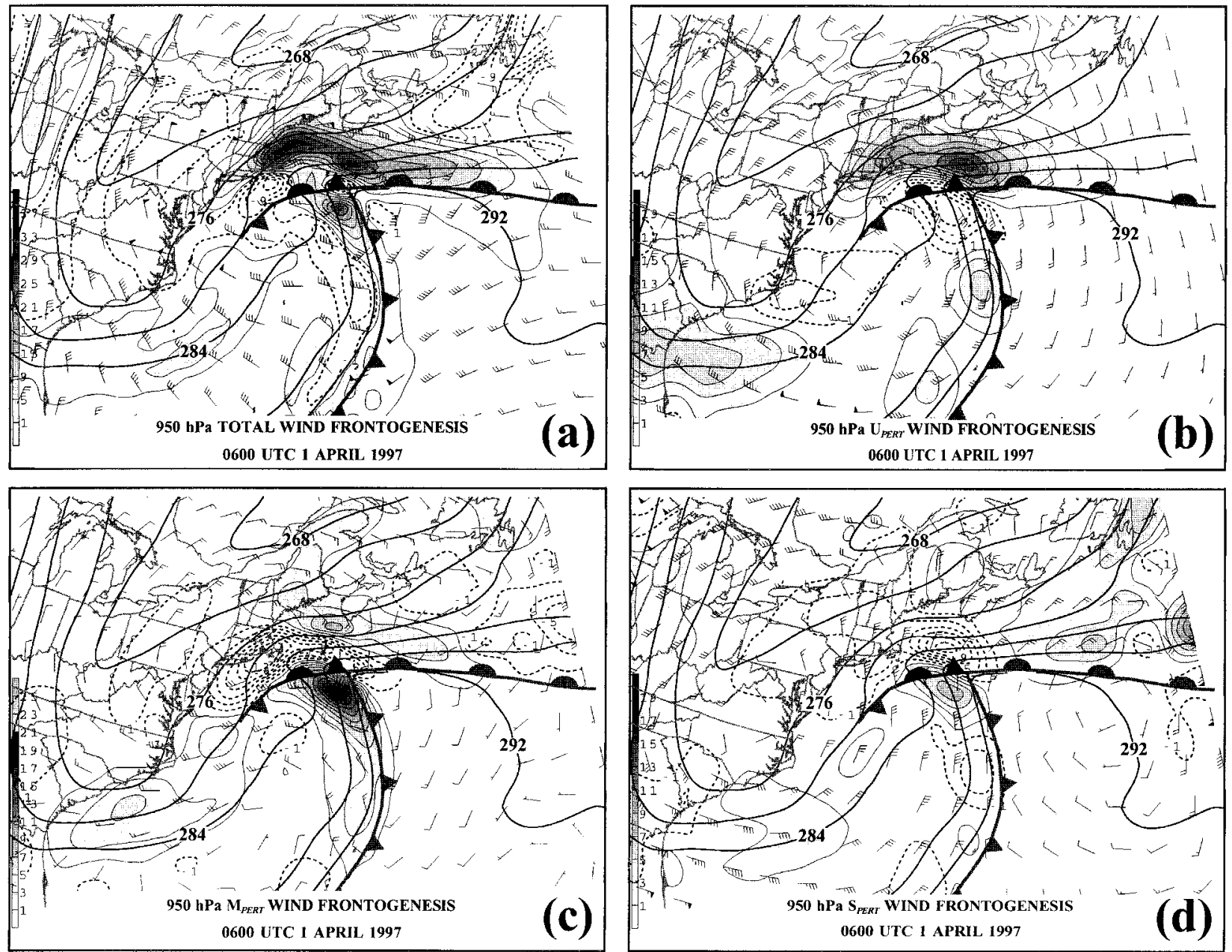

FIG. 14. (a) As for Fig. 12a except for 30-h forecast valid at 0600 UTC 1 Apr 1997. (b) As for Fig. 12b except for 30-h forecast valid at 0600 UTC 1 Apr 1997. (c) As for Fig. 12c except for 30-h forecast valid at 0600 UTC 1 Apr 1997. (d) As for Fig. 12d except for 30-h forecast valid at 0600 UTC 1 Apr 1997. (e) As for Fig. 13e except for 30-h forecast valid at 0600 UTC 1 Apr 1997. (f) As for Fig. 12f except for 24-h forecast valid at 0000 UTC 1 Apr 1997. (g) As for Fig. 12h except for 24-h forecast valid at 0000 UTC 1 Apr 1997.

warm frontal portion of the occluded thermal ridge and the bent-back extension of the warm front were very large. In fact, the unbalanced frontogenesis in these regions accounted for the vast majority of the total frontogenesis there. This is especially true in the bent-back portion of the warm front over southeastern New England and Long Island. Second, the unbalanced frontolysis along the cold front (except at its northern end) had continued to grow in magnitude and accounted for nearly all of the total frontolysis there. Thus, the analysis strongly suggests that the unbalanced flow was responsible for a substantial portion of the total distribution of frontogenesis at this point in the cyclone life cycle.

\section{d. 1200 UTC 1 April}

By 1200 UTC 1 April a lower-tropospheric T-bone frontal structure had developed with the intense portion of the warm front located just south of the Canadian
Maritime Provinces. The bent-back extension to the warm frontal zone had lengthened to the southwest and had evolved into a secondary cold frontal zone along the mid-Atlantic coast. The frontogenesis maximum along the warm front (Fig. 15a) was composed of a contribution along the primary warm front and one along the bent-back extension. The primary nondivergent forcing mechanism for this expansive warm frontogenesis region was the $\mathbf{U}_{\text {pert }}$ wind field (Fig. 15b), which captured the distribution of frontogenesis more accurately along the warm front near the peak of the warm sector than along the bent-back front. A significant, counteracting frontolysis region along the western portion of the warm front and its bent-back extension was associated with the $\mathbf{M}_{\text {pert }}$ circulation. The $\mathbf{M}_{\text {pert }}$ wind also forced a weak but spatially coherent region of frontogenesis along the secondary cold frontal zone at this time (Fig. 15c). The distribution of $\mathbf{S}_{\text {pert }}$ frontogenesis/ frontolysis remained largely unchanged (Fig. 15d). 

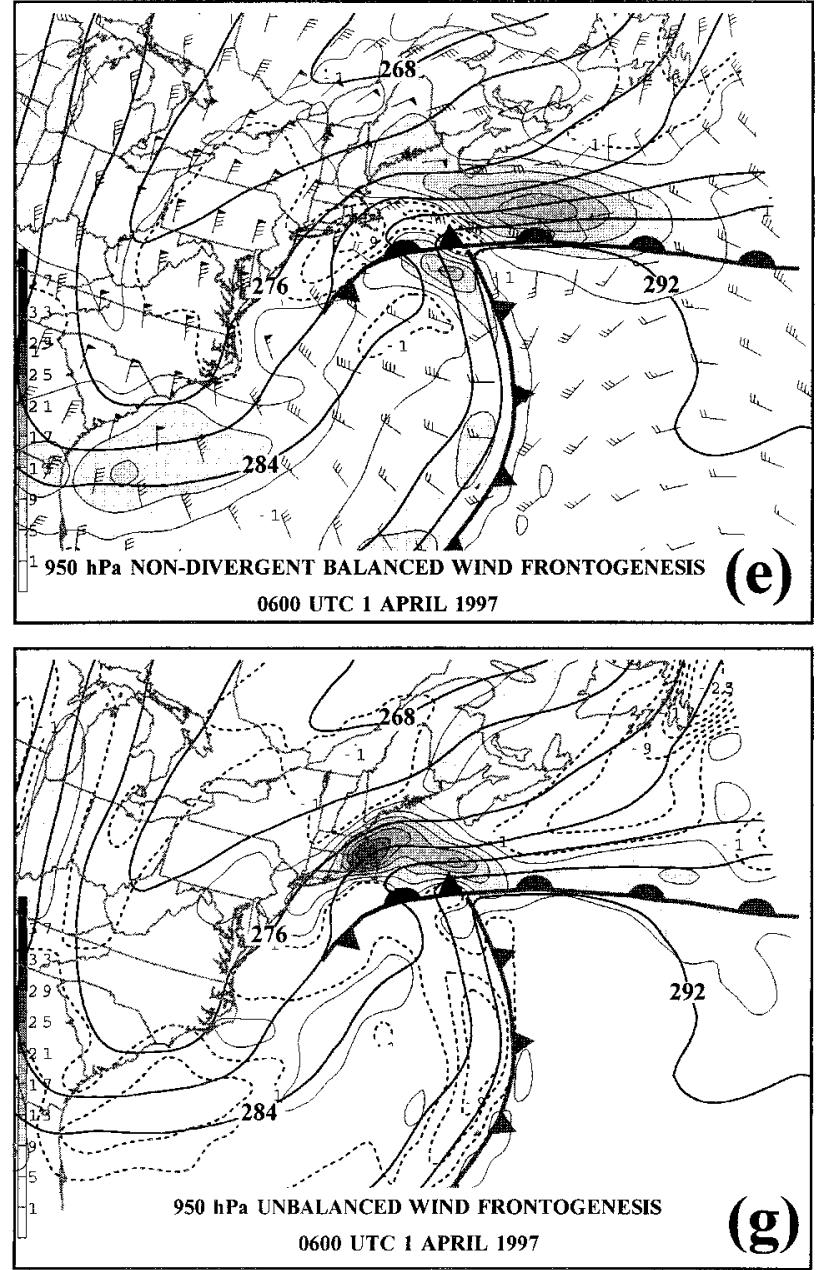

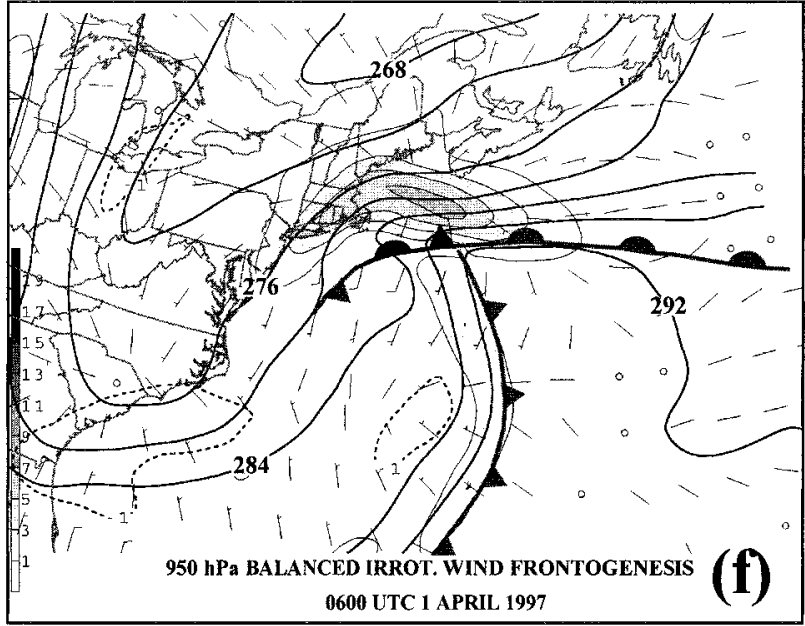

0600 UTC 1 APRIL 1997

FIG. 14. (Continued)

Large differences between the total nondivergent balanced frontogenesis (Fig. 15e) and the total wind frontogenesis (Fig. 15a) were evident again. A small portion (about 20\%) of this difference was accounted for by the irrotational balanced frontogenesis (Fig. 15f), which was largest along the western portion of the warm front and its bent-back extension. As was the case at prior times, the unbalanced frontogenesis contributed significantly to the total frontogenesis at this time (Fig. 15g). More than three fourths of the total frontogenesis associated with the bent-back front was forced by the unbalanced wind near that feature. The unbalanced frontogenesis was most significant also in the warm frontal portion of the occluded thermal ridge; east of there the balanced wind made the most significant contribution. The frontolysis that increasingly characterized the cold front was, again, a result of the unbalanced flow in the vicinity of that feature.

\section{Discussion}

In a recent paper, Davis et al. (1996) examined the degree of balance inherent in the flow associated with an explosively deepening cyclone, the Experiment on Rapidly Intensifying Cyclones over the Atlantic Intensive Observing Period 4 (ERICA IOP-4) storm. This was accomplished through use of nonlinear balance (Charney 1955) as the constraint for PV inversion. They found that, despite the large amount of ageostrophy that characterized that cyclone development, only a small portion of the flow was unbalanced (i.e., irretrievable through PV inversion). They were thus led to the conclusion that the extreme cyclone intensification was not dominated by unbalanced processes. The successful use of balanced diagnostics in that study compelled them to suggest that balanced diagnostics be employed in the investigation of mesoscale aspects of cyclones. One such mesoscale aspect-fronts and frontogenesis-is the focus of the present study.

Changes in the magnitude of the potential temperature gradient are a significant component of the evolution of the thermal structure of midlatitude cyclones. This quantity, frontogenesis, has traditionally been measured using the winds and temperatures at a single isobaric level as input to a frontogenesis function (e.g., Petterssen 

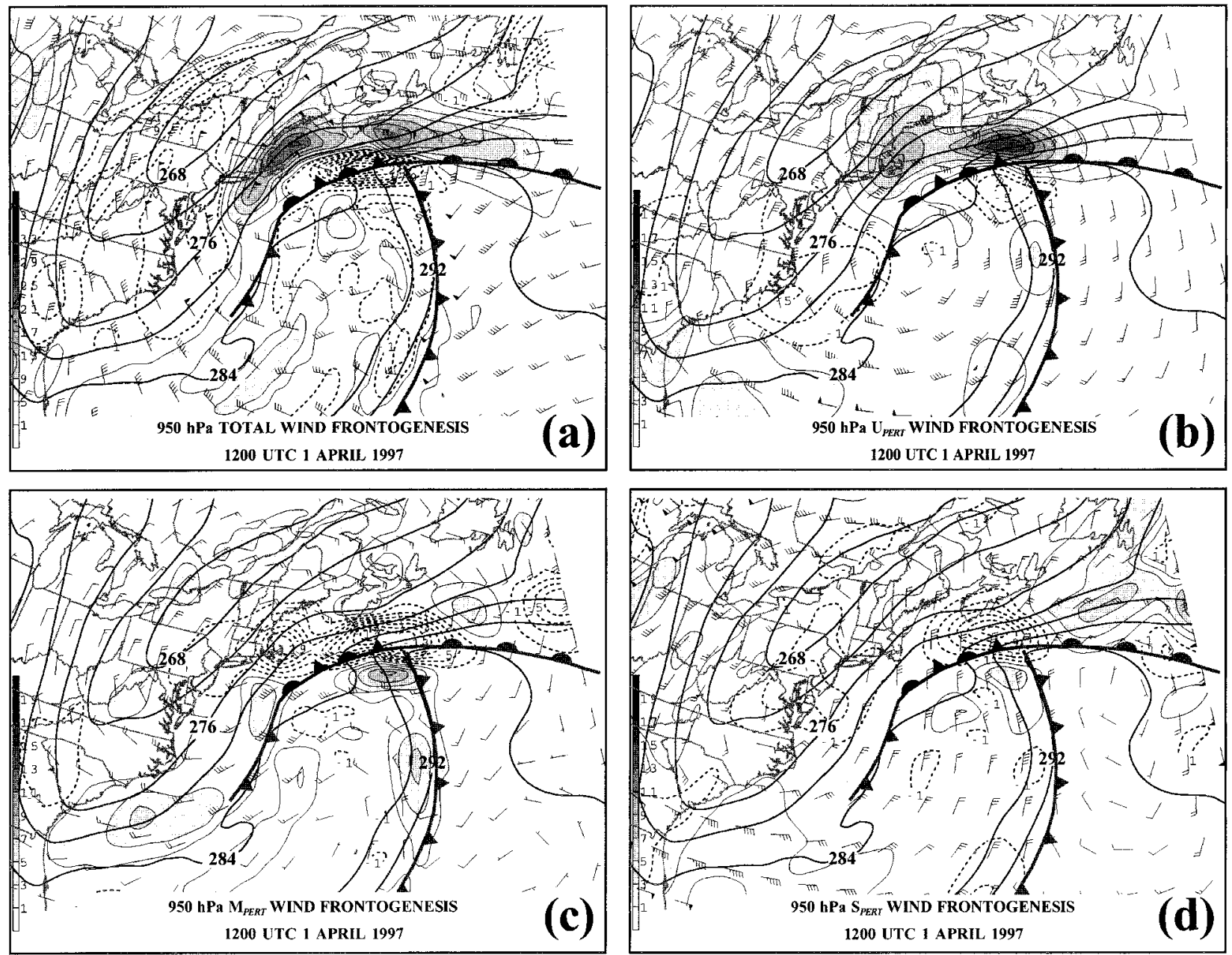

FIG. 15. (a) As for Fig. 12a except for 36-h forecast valid at 1200 UTC 1 Apr 1997. (b) As for Fig. 12b except for 36-h forecast valid at 1200 UTC 1 Apr 1997. (c) As for Fig. 12c except for 36-h forecast valid at 1200 UTC 1 Apr 1997. (d) As for Fig. 12d except for 36-h forecast valid at 1200 UTC 1 Apr 1997. (e) As for Fig. 13e except for 36-h forecast valid at 1200 UTC 1 Apr 1997. (f) As for Fig. 12f except for 24-h forecast valid at 0000 UTC 1 Apr 1997. (g) As for Fig. 12h except for 24-h forecast valid at 0000 UTC 1 Apr 1997.

1936; Miller 1948). In this paper we have used piecewise potential vorticity diagnostics to partition the circulation at any isobaric level into balanced, nondivergent contributions from the upper $\left(\mathbf{U}_{\text {pert }}\right)$, interior $\left(\mathbf{M}_{\text {pert }}\right)$, and surface $\left(\mathbf{S}_{\text {pert }}\right)$ PV anomalies. We have also considered the contributions made by both the balanced mean circulation and the balanced irrotational flow. These component circulations were then used as the kinematic input to a partitioned frontogenesis diagnostic we have termed piecewise frontogenesis. The piecewise frontogenesis method was employed to examine aspects of the evolution of the lower-tropospheric $(950 \mathrm{hPa})$ thermal structure of a major late winter storm that visited southern New England on 1 April 1997.

This cyclone, known as the April Fools' Day storm, was characterized by a robust warm frontal zone, a bentback extension to its southwest, and a deep occluded structure. These synoptic structural characteristics have been shown to arise in idealized cyclone experiments initialized in environments of cyclonic barotropic shear (Thorncroft et al. 1993; Wernli et al. 1998). Thorncroft et al. (1993) referred to these types of storms as "LC2" cyclones and showed that they are also associated with the development of cutoff disturbances at the tropopause. All of the aforementioned characteristics of LC2 cyclones were shared by the April Fools' Day storm. Piecewise frontogenesis may shed new light upon the factors responsible for elements of the evolution of the frontal structure of LC2-like cyclones. In the next paragraphs we discuss interpretations of the results of this analysis. We begin by considering the balanced nondivergent frontogenesis.

\section{a. Balanced frontogenesis}

As the cyclone evolved through the 18 -h period of our analysis, warm frontogenesis steadily became the most significant frontogenetic process (Figs. 12a, 13a, 

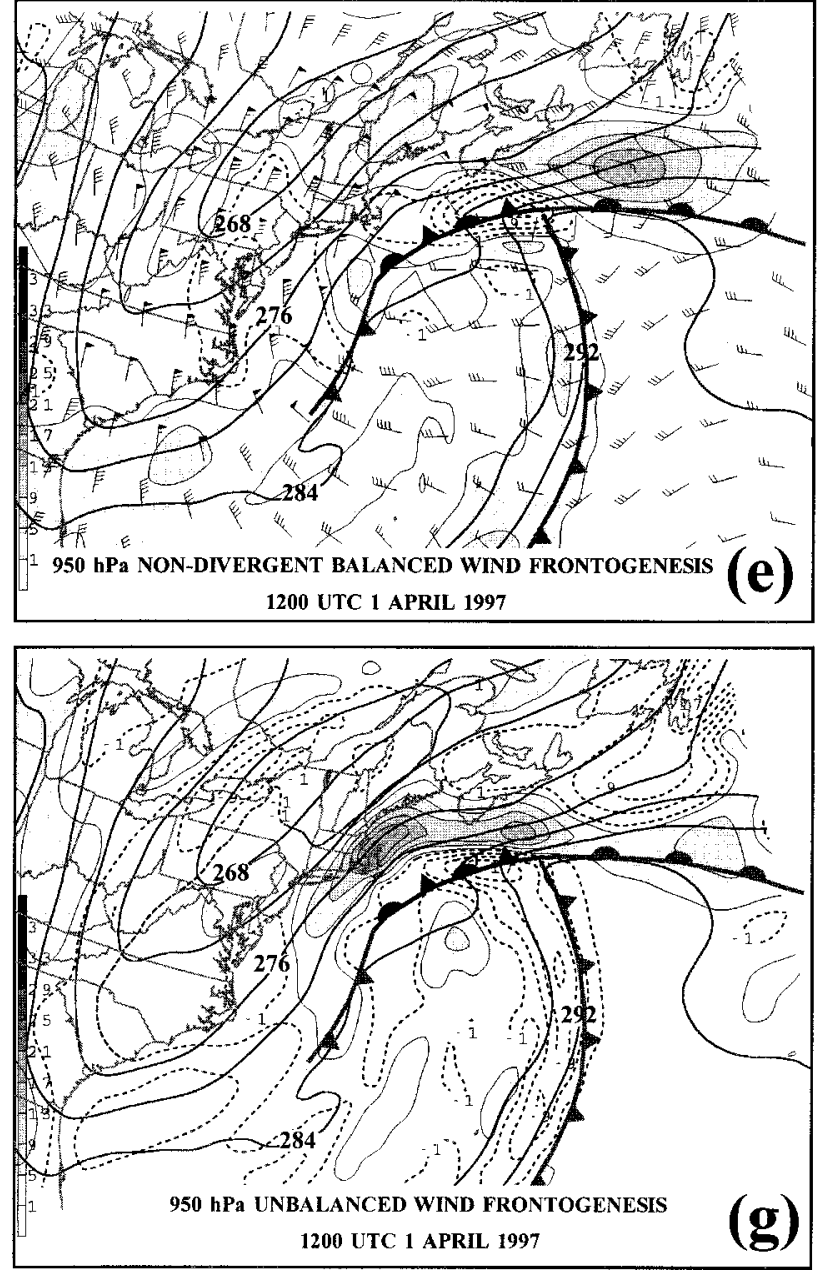

FIG. 15. (Continued) 14a, and 15a). At each analysis time the frontogenesis associated with the $\mathbf{U}_{\text {pert }}$ circulation was distributed much like the total frontogenesis. The $\mathbf{U}_{\text {pert }}$ frontogenesis along the warm front, as described earlier, was predominantly a result of shearing deformation across the front. The frontogenetic effect of this shearing deformation was enhanced by the fact that wind speeds poleward of the warm front were reduced as a result of variable penetration depth across the front. It is important to note that the center of the $\mathbf{U}_{\text {pert }}$ circulation was, at all times, located to the southwest of the occluded thermal ridge and peak of the warm sector. Thus, despite the fact that the cyclone became equivalently barotropic during the analysis interval, the relationship between the $\mathbf{U}_{\text {pert }}$ circulation and the gross thermal structure of the lower troposphere remained largely unchanged. As a result, the $\mathbf{U}_{\text {pert }}$ circulation consistently exerted a considerable frontogenetic forcing on the warm frontal zone. The fact that the $\mathbf{U}_{\text {pert }}$ circulation was associated with a nearly cutoff disturbance aloft in the present case provides a possible explanation for the predominance of warm fronts in LC2-like storms; namely, that the $\mathbf{U}_{\text {pert }}$ circu-

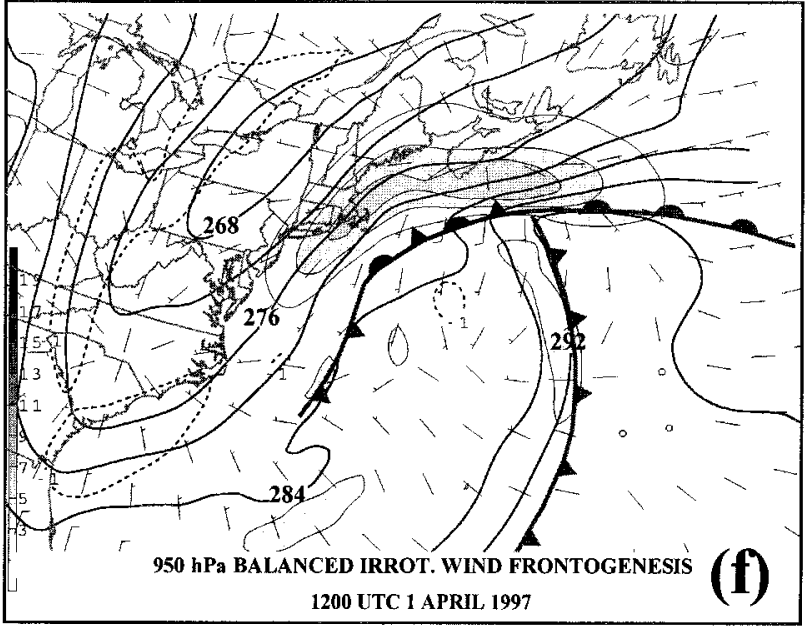

lation in such storms strongly favors the production of strong warm frontal zones while providing only weak and spatially intermittent forcing for cold fronts.

The $\mathbf{M}_{\text {pert }}$ circulation, meanwhile, produced frontolysis, which steadily grew, in the vicinity of the thermal ridge and bent-back front during the analysis period. The frontolytic tendency of the $\mathbf{M}_{\text {pert }}$ circulation was influenced by a number of circumstances particular to this cyclone. First, the heavy precipitation (which led directly to the production of the diabatically generated PV anomaly) was consistently centered about the occluded thermal ridge (Martin 1999a, b). As a result, the PV anomaly remained along the coast throughout the analysis period. Thus, at each analysis time, the $\mathbf{M}_{\text {pert }}$ winds were stronger over the warm, less stably stratified column of air over the ocean than over the land. The strong west winds just south of New England, acting upon north-south-oriented isentropes, produced strong frontolysis in the region where the bent-back front was developing.

The sudden disappearance of the strong frontolysis in the bent-back region at 1200 UTC 1 April resulted 
from the fact that the shape of the anomaly changed significantly during the analysis period. The April Fools' Day storm was strongly equivalently barotropic by 1200 UTC 1 April. Thus, the initially localized PV anomaly had been "axisymmetrized" by the macroscale circulation of the cyclone rendering the PV contours and isentropes nearly parallel to one another on isobaric surfaces in the vicinity of the bent-back front. Thus, the $\mathbf{M}_{\text {pert }}$ circulation exerted no frontogenetic forcing there. The frontolysis east of Massachusetts remained vigorous, however, especially south of Nova Scotia at the eastern periphery of the PV anomaly. In fact, the $\mathbf{M}_{\text {pert }}$ frontolysis there accounted for a considerable portion of the total frontolysis in that region.

A noticeable evolution in the balanced irrotational frontogenesis is evident in the 18 -h analysis period as well. Initially, the irrotational frontogenesis was significant mainly along the developing cold front. The dominance of warm frontogenesis was quickly asserted, however, by 0000 UTC 1 April. The continued growth of the irrotational frontogenesis along the warm front and its bent-back extension was a notable characteristic of this evolution. The combination of the $\mathbf{U}_{\text {pert }}$ and irrotational frontogenesis in these regions accounted for a significant portion of the total frontogenesis along the bent-back feature at 0600 and 1200 UTC 1 April. However, the frontolytic contribution made by $\mathbf{M}_{\text {pert }}$ and $\mathbf{S}_{\text {pert }}$ nearly exactly balanced this frontogenesis at these times.

\section{b. Unbalanced frontogenesis}

Despite the similarity in distribution between the $\mathbf{U}_{\text {pert }}$ and total frontogenesis at all analysis times, the total wind frontogenesis exceeded the total balanced frontogenesis throughout the period and led to a steadily increasing unbalanced flow contribution to the frontogenesis in the occluded sector of this cyclone. In fact, more than half of the lower-tropospheric frontogenesis in the occluded quadrant, including a considerable portion of the development of the bent-back front, was forced by the unbalanced flow.

It is important to note that this unbalanced frontogenesis was not the result of large unbalanced winds in the occluded quadrant. The unbalanced winds were generally on the order of $5-10 \mathrm{~m} \mathrm{~s}^{-1}$ in this portion of the storm (not shown) and so were not significantly different from those reported by Davis et al. (1996). Since frontogenesis depends on the product of derivatives of the wind and potential temperature fields it can be large in the presence of large $\nabla \theta$ even if the winds are rather weak. The results from this case suggest that, despite the relative smallness of the unbalanced flow, its distribution relative to frontal zones can have a profound effect on the thermal structure and evolution of midlatitude cyclones.

Certain cautions must be raised when interpreting the results of this one case, however. Most importantly, the amount of unbalanced flow is impacted by the details of the tendency calculations used to recover the balanced irrotational winds. The prognostic system of equations used in making the tendency calculations for the balanced system includes an omega equation that can be solved with or without the inclusion of moisture. Inclusion of moisture (not present in our calculations since inclusion prevented the iterative solution from converging with our $1^{\circ} \times 1^{\circ}$ data) is likely to provide stronger and more focused vertical motions that, in turn, lead to stronger and more focused irrotational winds. The April Fools' Day cyclone was clearly unusual with regard to the precipitation associated with it. The fact that much of that precipitation was located in the occluded quadrant means that neglect of the moisture in the tendency calculations had its greatest impact there. However, the inclusion of moisture would have to increase the irrotational frontogenesis by a factor of 2 or more in order that the unbalanced frontogenesis be displaced as the predominant contributor to the total frontogenesis in the occluded quadrant of the cyclone. As a means of determining what portion of the unbalanced frontogenesis arises from purely dynamical considerations, we envision employment of piecewise frontogenesis diagnostics in a dry, idealized numerical simulation of a cyclone. In this way, a clearer and more general conclusion regarding the nature of unbalanced frontogenesis in midlatitude cyclones may be achieved.

Another obstacle to deriving the maximum insight from piecewise diagnostics such as those used here is determination of a dynamically satisfying method of computing the basic state. Use of a time mean is convenient but flawed. Three primary flaws result from 1) the effect of quasi-stationary features on the mean, 2) the lack of dynamical significance associated with the mean wind, and 3) the subjective nature of choosing an appropriate time interval. The first problem is especially troublesome when trying to study the effect of interior PV anomalies that, once created, tend to grow and decay in roughly the same location. In defining our time mean, we chose to exclude all times at which a midlevel PV feature with a magnitude greater than 1 PVU existed. Though subjective, this method successfully minimized the amount of interior PV included in the mean.

The ease with which a time mean can be computed outweighs the aforementioned flaws for some, though not all, applications. Careful circumspection is required, based upon the features of interest and the case in question, to determine appropriate time intervals. In a case where interior PV is not a central issue and the features of interest progress rapidly through the domain a shorter time interval may be sufficient. Recently, Hakim et al. (1996) and M. Morgan (1998, personal communication) have suggested the wavelet transform method for thoroughly isolating and extracting the anomalous portion of the flow. Another possibility is to use a "dynamically meaningful" basic state such as that defined by Morgan (1994). Both methods involve substantially more work than the time mean method employed here. However, 
these alternative methods also promise to minimize the caveats mentioned above, presumably leading to more physically satisfying results.

\section{Conclusions}

From approximately 1200 UTC 31 March until 1200 UTC 1 April 1997 a late-season snowstorm, referred to here as the April Fools' Day storm, brought record heavy snows and strong winds to southern New England. The event was characterized by a significant uppertropospheric PV anomaly, an intense midtropospheric PV anomaly, and a distinct surface thermal wave with associated warm and cold fronts. The method of piecewise potential vorticity inversion (Davis and Emanuel 1991) was employed, using the output from a successful numerical simulation of this storm, to diagnose the development and frontal evolution of this cyclone. It was found that the initial cyclogenesis was a result of winds associated with the upper-tropospheric PV anomaly amplifying a surface thermal wave. In the later stages of the cyclone's evolution, the cyclonic circulation associated with an interior PV anomaly contributed constructively to the total surface circulation. The interior PV anomaly was generated by latent heat release associated with the heavy precipitation produced as a consequence of the strong warm frontogenesis that characterized this case. Mutual intensification was not observed between the winds associated with the surface thermal wave and the upper PV anomaly. However, the winds associated with the interior PV anomaly did contribute to deforming the shape of the upper PV anomaly.

To gain insight into the interaction of PV anomalies and frontal baroclinic zones in this case, piecewise PV inversion was extended to examine the frontogenesis forced by the winds associated with discrete pieces of the total PV field-what we term piecewise frontogenesis. In this particular case, the nondivergent balanced winds associated with PV anomalies in the upper, interior, and surface layers, along with the balanced irrotational wind, were used to examine their respective effects on the low-level frontal evolution of the April Fools' Day storm. This computation revealed that early in the cyclone's life cycle, the total frontogenesis was largely forced by balanced flow, particularly that portion of it associated with the upper-level PV anomaly. In fact, throughout the remainder of the cyclone life cycle, the upper-level contribution to the frontogenesis retained a distribution similar to that of the total frontogenesis. After occlusion, however, significant unbalanced frontogenesis developed, particularly in the occluded quadrant of the cyclone and along the bent-back front. Despite the exclusion of moisture in our tendency calculations, the results described here point to the potentially significant role that unbalanced motions have in the development and maintenance of lower-tropospheric frontal structures in midlatitude cyclones. Further work undertaken to employ this piecewise front- ogenesis extension of PV thinking to examine the structure and evolution of other frontal features, in both maritime and continental cyclones, will surely produce additional insight into the factors that influence the frontal evolution of midlatitude cyclones.

Acknowledgments. The thoughtful comments of Dr. Michael Morgan have been most helpful in the course of this work. The comments of Dr. Christopher Davis and two anonymous reviewers are also appreciated. This paper represents a portion of the first author's M.S. thesis at the University of Wisconsin. The work was supported by the National Science Foundation under Grant ATM-9505849.

\section{REFERENCES}

Bjerknes, J., and H. Solberg, 1922: Life cycle of cyclones and the polar front theory of atmospheric circulation. Geofys. Publ., 3, $1-18$.

Bresky, W. C., and S. J. Colucci, 1996: A forecast and analyzed cyclogenesis event diagnosed with potential vorticity. Mon. Wea. Rev., 124, 2227-2244.

Bretherton, F. P., 1966: Critical layer instability in baroclinic flows. Quart. J. Royal Meteor. Soc., 92, 325-334.

Charney, J., 1955: The use of the primitive and balance equations. Tellus, 7, 22-26.

Chen, C., and W. R. Cotton, 1983: A one-dimensional simulation of the stratocumulus capped mixed layer. Bound.-Layer Meteor., 25, 289-321.

Cotton, W. R., G. J. Tripoli, R. M. Rauber, and E. A. Mulvihill, 1986: Numerical simulation of the effects of varying ice crystal nucleation rates and aggregation processes on orographic snowfall. J. Climate Appl. Meteor., 25, 1658-1680.

Davis, C. A., 1992a: Piecewise potential vorticity inversion. J. Atmos. Sci., 49, 1397-1411.

_ 1992b: A potential vorticity diagnosis of the importance of initial structure and condensational heating in observed cyclogenesis. Mon. Wea. Rev., 120, 2409-2428.

— cyclogenesis. Mon. Wea. Rev., 119, 1929-1953.

_ M. T. Stoelinga, and Y.-H. Kuo, 1993: The integrated effect of condensation in numerical simulations of extratropical cyclogenesis. Mon. Wea. Rev., 121, 2309-2330.

_ E. D. Grell, and M. A. Shapiro, 1996: The balanced dynamical nature of a rapidly intensifying oceanic cyclone. Mon. Wea. Rev., 124, 3-26.

Eliassen, A., 1962: On the vertical circulations in frontal zones. Geofys. Publ., 24, 147-160.

Emanuel, K. A., 1991: A scheme for representing cumulus convection in large-scale models. J. Atmos. Sci., 48, 2313-2335.

Ertel, H., 1942: Ein Neuer hydrodynamischer Wirbelsatz. Meteor. Z., 59, 271-281.

Flatau, P., G. J. Tripoli, J. Verlinde, and W. R. Cotton, 1989: The CSU RAMS cloud microphysical module: General theory and code documentation. Tech. Rep. 451, Dept. of Atmospheric Sciences, Colorado State University, 88 pp. [Available from Dept. of Atmospheric Sciences, Colorado State University, Fort Collins, CO 80523.]

Hakim, G. J., D. Keyser, and L. F. Bosart, 1996: Diagnosis of tropopause-based coherent structures. Preprints, Seventh Conf. on Mesoscale Processes, Reading, United Kingdom, Amer. Meteor. Soc., 17-22.

Hoskins, B. J. 1991: Towards a PV- $\theta$ view of the general circulation. Tellus, 43AB, 27-35.

, and P. Berrisford, 1988: A potential vorticity perspective of the storm of 15-16 October '87. Weather, 43, 122-129. 
M. E. McIntyre, and A. W. Robertson, 1985: On the use and significance of isentropic potential vorticity maps. Quart. J. Roy. Meteor. Soc., 111, 877-946.

Kleinschmidt, E., 1957: Cyclones and anticyclones. Dynamic Meteorology, Handbuch der Physik, S. Flugge, Ed., Vol. 48, SpringerVerlag, 112-154.

Martin, J. E., 1998: The structure and evolution of a continental winter cyclone. Part I: Frontal structure and the occlusion process. Mon. Wea. Rev., 126, 303-328.

— 1999a: Quasigeostrophic forcing for ascent in the occluded sector of cyclones and the trowal airstream. Mon. Wea. Rev., 127, 66-84.

_ 1999b: The separate roles of geostrophic vorticity and deformation in the mid-latitude occlusion process. Mon. Wea. Rev., 127, 2404-2418.

Miller, J. E., 1948: On the concept of frontogenesis. J. Meteor., 5, 169-171.

Morgan, M. C., 1994: An observationally and dynamically determined basic state for the study of synoptic scale waves. Ph.D. thesis, Massachusetts Institute of Technology, $123 \mathrm{pp}$. [Available from Michael C. Morgan, University of Wisconsin-Madison, 1225 W. Dayton St., Madison, WI 53706.]

_ 1999: Using piecewise potential vorticity inversion to diagnose frontogenesis. Part I: A partitioning of the $\mathrm{Q}$ vector applied to diagnosing surface frontogenesis and vertical motion. Mon. Wea. Rev., 127, 2796-2821.

_, and J. Nielsen-Gammon, 1998: Using tropopause maps to diagnose midlatitude weather systems. Mon. Wea. Rev., 126, 25552579.

Nielsen, J., C. Davis, and D. Keyser, 1991: Upper-level frontogenesis made easy? Preprints, First Int. Symp. on Winter Storms, New Orleans, LA, Amer. Meteor. Soc., 82-87.

Petterssen, S., 1936: Contribution to the theory of frontogenesis. Geofys. Publ., 11 (6), 127.

Ramos, R. A., 1997: The role of latent heat release on the formation of an upper tropospheric outflow jet. M.S. thesis, Department of Atmospheric and Oceanic Sciences, University of Wisconsin-
Madison, 149 pp. [Available from University of WisconsinMadison, Dept. of Atmospheric and Oceanic Sciences, 1225 W. Dayton St., Madison, WI 53706.]

Raymond, D. J., 1992: Nonlinear balance and potential vorticity thinking at large Rossby number. Quart. J. Roy. Meteor. Soc., 118, 987-1015.

Rossby, C. G., 1940: Planetary flow patterns in the atmosphere. Quart. J. Roy. Meteor. Soc., 66, 68-87.

Sadourny, R., 1975: The dynamics of finite-difference models of the shallow water equations. J. Atmos. Sci., 32, 680-689.

Sawyer, J. S., 1956: The vertical circulation at meteorological fronts and its relation to frontogenesis. Proc. Roy. Soc. London, A234, 346-362.

Stoelinga, M. T., 1996: A potential vorticity-based study of the role of diabatic heating and friction in a numerically simulated baroclinic cyclone. Mon. Wea. Rev., 124, 849-874.

Throncroft, C. D., B. J. Hoskins, and M. E. McIntyre, 1993: Two paradigms of baroclinic-wave life-cycle behaviour. Quart. $J$. Roy. Meteor. Soc., 119, 17-55.

Tremback, C. J., and R. Kessler, 1985: A surface temperature and moisture parameterization for use in mesoscale numerical models. Preprints, Seventh Conf. on Numerical Weather Prediction, Montreal, PQ, Canada, Amer. Meteor. Soc., 355-358.

- J. Powell, W. R. Cotton, and R. A. Pielke, 1987: The forwardin-time upstream advection scheme: Extension to higher orders. Mon. Wea. Rev., 115, 540-555.

Tripoli, G., J., 1992a: An explicit three-dimensional nonhydrostatic numerical simulation of a tropical cyclone. Meteor. Atmos. Phys., 49, 229-254.

— 1992b: A nonhydrostatic numerical model designed to simulate scale interaction. Mon. Wea. Rev., 120, 1342-1359.

Wernli, H., R. Fehlmann, and D. Luthi, 1998: The effect of barotropic shear on upper-level induced cyclogenesis: Semigeostrophic and primitive equation numerical simulations. J. Atmos. Sci., 55, 2080-2094.

Whitaker, J. S., and C. A. Davis, 1994: Cyclogenesis in a saturated environment. J. Atmos. Sci., 51, 889-907. 